\title{
Costs and benefits in perceptual categorization
}

\author{
W. TODD MADDOX and COREY J. BOHIL \\ University of Texas, Austin, Texas
}

\begin{abstract}
Observers categorized perceptual stimuli when the category costs and benefits were manipulated across conditions, and costs were either zero or nonzero. The cost-benefit structures were selected so that performance across conditions was equivalent with respect to the optimal classifier. Each observer completed several blocks of trials in each of the experimental conditions, and a series of nested models was applied to the individual observer data from all conditions. In general, performance became more nearly optimal as observers gained experience with the cost-benefit structures, but performance reached asymptote at a suboptimal level. Observers behaved differently in the zero- and nonzero-cost conditions, performing consistently worse when costs were nonzero. A test of the hypothesis that observers weight costs more heavily than benefits was inconclusive. Some aspects of the data supported this differential weighting hypothesis, but others did not. Implications for current theories of cost-benefit learning are discussed.
\end{abstract}

Every day, we make important decisions based on uncertain information. For example, we might decide to "bring" or "not bring" an umbrella to work solely on the basis of uncertain predictors of rain, such as the degree of overcast. This is a categorization problem because there are many degrees of overcast that one might observe, but only two potential decisions. There might be no or a few clouds, and we might decide "not to bring" an umbrella to work, or there might be many or a sky full of clouds, and we might decide "to bring" an umbrella to work. Often, the costs and benefits associated with each categorization decision are different. If we bring an umbrella and it rains, we benefit by staying dry; the benefit might be greater if we are wearing a suit than if we are wearing a $t$-shirt and jeans. If we fail to bring an umbrella and it rains, we get wet. This cost might be greater if we are wearing expensive clothes. Costs and benefits can strongly impact the decisions we make. For example, we might decide to "bring" an umbrella if wearing expensive clothes or "not bring" an umbrella if wearing a t-shirt and jeans, even though the degree of overcast is nearly identical in both cases.

The perceptual and cognitive processes involved in solving categorization problems of this sort have been studied extensively (Ashby, 1992; Busemeyer \& Myung, 1992; Green \& Swets, 1966; Macmillan \& Creelman, 1991; Maddox, 1995; Maddox \& Ashby, 1993; Maddox \&

This research was supported in part by National Science Foundation Grant SBR-9796206 and NIH Grant R01 MH59196. The authors thank Greg Ashby and Jerome Busemeyer for many interesting discussions that influenced this work. Special thanks go to Jerome Busemeyer, Thomas Ward, and one anonymous reviewer who provided comments on an earlier version of the manuscript. The authors also thank Candace Blair for help with the data collection. Correspondence should be addressed to W. T. Maddox, Department of Psychology, Mezes Hall 330, University of Texas, Austin, TX 78712 (e-mail: maddox@psy. utexas.edu).
Bohil, 1998a, 1998b; Nosofsky, 1986; Stevenson, Busemeyer, \& Naylor, 1991; von Winterfeldt \& Edwards, 1982). One popular approach has been to compare human performance with that of the optimal classifier-a hypothetical device whose categorization decisions maximize longrun reward. When observed performance is suboptimal, the goal has been to identify the locus of the performance suboptimality.

Despite anecdotal evidence that suggests that differential costs and benefits have a strong impact on everyday categorization decisions, few categorization studies have manipulated systematically costs and benefits. The few studies that have examined costs and benefits have focused only on unequal benefits while holding costs fixed at zero (e.g., Bohil \& Maddox, in press; Maddox \& Bohil, 1998a; however, see Busemeyer \& Myung, 1992). The effects of nonzero costs have been examined in the decisionmaking literature, and a common finding is that costs are weighted more heavily than benefits (e.g., Kahneman \& Tversky, 1979; see also Higgins, 1987). In nearly all of this work, word problems were used in which the relevant information was presented explicitly (Kahneman \& Tversky, 1973; Tversky \& Kahneman, 1974, 1980); however, a large body of categorization research suggests that categories are better learned implicitly through trial-by-trial experience with category members and trial-by-trial feedback (e.g., Estes, Campbell, Hatsopoulos, \& Hurwitz, 1989; Holyoak \& Spellman, 1993; Koehler, 1996; Maddox \& Ashby, 1993). We propose a formal model that instantiates this differential weighting of costs over benefits. We tested this differential weighting hypothesis (DWH) by applying the model to the categorization data collected in the present study.

The goals of the present study were many. First and foremost, we attempted to bridge the gap between categorization and decision-making research by manipulating 
systematically both costs and benefits within the framework of a single categorization task. Although categorization was our primary interest, we tried to draw parallels between these two important areas of research. In particular, when appropriate, we tried to relate the different terminology used in the two areas. Second, we examined performance in zero-cost and nonzero-cost conditions and compared performance with that of the optimal classifier. To facilitate a comparison with the optimal classifier, the costs and benefits were constrained in such a way that the performance of the optimal classifier was identical across conditions. Third, we studied the time course of cost-benefit learning by having observers complete several blocks of trials in each experimental condition and by analyzing the data from each block of trials separately. The details of these analyses are reported in the Appendix and should provide a rich database for testing current and future models of cost-benefit learning in categorization. Finally, we provided an initial test of the DWH as applied to categorization.

In this paper, we describe briefly the optimal classifier and the theoretical framework (decision bound theory) within which the present study operated, and we review briefly the relevant categorization and decision-making literature. Then, we outline the experiment and the methods, and we present the results and theoretical analyses. Finally, we conclude with some general comments.

\section{Decision Bound Theory and the Optimal Classifier}

Consider the situation facing a medical doctor who must classify a patient's disease into one of two categories, $A$ or $B$. Suppose the patient is given medical test $X$, which is diagnostic of the two diseases. In addition, suppose that the outcomes of test $X$ for diseases $A$ and $B$ are normally distributed with means $\mu_{A}$ and $\mu_{B}$, and variances $\sigma_{A}^{2}$ and $\sigma_{B}^{2}$, as depicted in Figure 1a. The optimal classifier records perfectly the test result, denoted $x$. (In the decision-making literature, the optimal classifier is derived from the "expected utility rule"; e.g., Stevenson et al., 1991; Yates, 1990. Once we outline the details of the optimal classifier, we will detail its relation to the expected utility rule and other constructs from the decisionmaking literature.) In other words, given a fixed physical input, the optimal classifier will show no variability in the perceptual representation. ${ }^{1}$ The optimal classifier has perfect knowledge of the distribution of test results for each disease category (i.e., the form and parameters of the distribution). This information is used to construct the optimal decision function, which is computed from the likelihood ratio of the two category distributions,

$$
l_{\mathrm{o}}(x)=f(x \mid B) / f(x \mid A),
$$

where $f(x \mid i)$ denotes the likelihood of test result $x$ given disease category $i$. If test result $x$ is more likely to result from disease $B$ than from disease $A$, then the likelihood ratio will be greater than one. Conversely, if the test result is more likely to result from disease $A$ than from disease $B$, then the likelihood ratio will be less than one.

The optimal classifier has perfect knowledge of the costs associated with incorrect diagnoses, and the benefits associated with correct diagnoses. This information is used to construct the optimal decision criterion,

$$
\beta_{\mathrm{o}}=\left(V_{a A}-V_{b A}\right) /\left(V_{b B}-V_{a B}\right),
$$

where $V_{a A}$ and $V_{b B}$ denote the benefits associated with correct diagnoses, and $V_{b A}$ and $V_{a B}$ denote the costs associated with incorrect diagnoses (letters in lowercase denote responses, and letters in uppercase denote categories). The costs and benefits might vary depending on the severity of the disease. For example, suppose that disease $A$ is life threatening, whereas disease $B$ is not. If the doctor correctly diagnoses the patient as suffering from disease $A$, the benefit could be large, such as an early diagnosis that saves the patient's life. A correct disease $B$ diagnosis, on the other hand, might yield a smaller benefit. Incorrectly diagnosing the patient as suffering from disease $B$ (not life threatening) instead of disease $A$ (life threatening) could have a large cost, such as a loss of life. Although potentially "nerve racking," the cost of an incorrect disease $A$ diagnosis would likely be less severe.

The optimal classifier (e.g., Green \& Swets, 1966) uses $l_{\mathrm{o}}(x)$ and $\beta_{\mathrm{o}}$ to construct the optimal decision rule (derived from expected utility theory):

$$
\begin{aligned}
& \text { If } l_{\mathrm{o}}(x)>\beta_{\mathrm{o}} \text {, then respond "B"; } \\
& \text { otherwise, respond "A." }
\end{aligned}
$$

When the costs and benefits lead to no bias, $\beta_{\mathrm{o}}=1$. In other words, the diagnosis would be driven completely by the likelihood ratio, as depicted by the $\beta_{\mathrm{o}}=1$ decision criterion in Figure 1a. If the likelihood of disease $A$ exceeds that of disease $B$, then the patient will be diagnosed with disease $A$. If the likelihood of disease $B$ exceeds that of disease $A$, then the patient will be diagnosed with disease $B$. When $V_{a A}-V_{b A}>V_{b B}-V_{a B}, \beta_{\mathrm{o}}>1$. For example, suppose $\beta_{0}=3$, as depicted in Figure la. Under these conditions, the likelihood of disease $B$ would have to be at least three times larger than the likelihood of disease $A$ for the patient to be diagnosed with disease $B$. This is a possible scenario if disease $A$ is life threatening and disease $B$ is not. It would be much worse to incorrectly diagnose the patient as suffering from a non-life-threatening disease (when his/her life was actually in danger), than it would be to incorrectly diagnose the patient as suffering from a life-threatening disease (when his/her life was not actually in danger). The partition between the " $A$ " and " $\mathrm{B}$ " response regions [where $l_{\mathrm{o}}(x)=\beta_{\mathrm{o}}$ ] is called the $o p$ timal decision bound.

The optimal decision bound is constructed from the "objective" or "true" category information. For example, the optimal classifier has knowledge of the "objective" costs and benefits. A large body of decision-making research suggests that people do not use the objective costs and benefits but rather base their decisions on subjective 
costs and benefits that are directly related to the objective values (e.g., Stevenson et al., 1991; Yates, 1990). To distinguish the subjective values from the objective values, decision theorists use the term utility to denote the subjective worth of an objective value. Thus, within the framework of decision theory, each of our $V_{i j}$ terms (where $i=$ $a$ or $b$, and $J=A$ or $B$ ) should be converted into a subjective utility denoted $u\left(V_{i J}\right)$, where $u$ describes the functional relationship between the subjective and objective values. When the costs and benefits are quantitative, as is the case with money, it is reasonable to assume that more is always preferred over less. In other words, the utility of a given outcome is monotone, increasing with the objective value of the outcome. This is a fairly weak constraint on the functional relationship between utilities and objective values. As a result, many functions are possible. However, decision theorists have focused on only a few. In particular, concave, convex, and linear relationships have been investigated. Although a detailed examination of these functional relations and their implications for decision-making and categorization problems is beyond the scope of this article, the linear function is most directly relevant to the present study. Because the optimal decision criterion, $\beta_{0}$, is derived from the ratio of intervals, it is invariant under any linear transformation. In other words, as long as the utility function, $u$, is linear, then the optimal decision criterion is equivalent to the expected utility criterion. Thus, within the framework of decision theory, the focus of the present article is on linear utility functions. This is a strong assumption, but one that should hold (approximately) for the small range of monetary values in the present study. For ease of exposition, we will generally use the term optimal decision criterion; however, when relevant and informative, we will relate the discussion back to decision theory.

The optimal classifier decision rule (Equation 3) has been rejected as a model of human performance, but, in many cases, performance approaches that of the optimal classifier as the observer gains experience with the task. Ashby and colleagues argued that the observer attempts to respond in accordance with the optimal classifier but fails because of various suboptimalities in perceptual and cognitive processing (Ashby, 1992; Ashby \& Lee, 1991; Ashby \& Maddox, 1993, 1994; Ashby \& Townsend, 1986; Maddox \& Ashby, 1993; R. D. Thomas, 1995). Ashby (1992; see also Maddox \& Ashby, 1993) proposed a series of decision bound models that can be used to test specific hypotheses about the locus of performance suboptimalities. Two suboptimalities that are inherent in humans (and other organisms) are perceptual and criterial noise. Perceptual noise exists because there is trial-bytrial variability in the perceptual information associated with each stimulus. Thus, the observer's percept of stimulus $i$, on any trial, is given by $x_{p i}=x_{i}+e_{p}$, where $x_{i}$ is the observer's mean percept, and $e_{p}$ is a random variable that represents the effects of perceptual noise. At the cognitive level, there is trial-by-trial variability in the observer's memory for the decision criterion (termed crite- rial noise $).{ }^{2}$ Because of criterial noise, the decision criterion used on any trial is given by $\beta_{c}=\beta+e c$, where $\beta$ is the observer's average decision criterion, and $e_{c}$ is a random variable that represents the effects of criterial noise (assumed to be univariate normally distributed).

Because perceptual noise and criterial noise exist, the human observer cannot attain the level of performance reached by the optimal classifier (i.e., cannot maximize long-run reward). Even so, decision bound theory assumes that the observer attempts to use the same strategy as the optimal classifier, but with less success due to the effects of perceptual and criterial noise (and other possible suboptimalities). Hence, the simplest decision bound model is the optimal decision bound model. The optimal decision bound model is identical to the optimal classifier (Equation 3) except that perceptual noise and criterial noise are incorporated into the decision rule. Specifically,

$$
\begin{array}{r}
\text { If } l_{\mathrm{o}}\left(x_{p i}\right)>\beta_{\mathrm{o}}+e_{c} \text {, then respond "B"; } \\
\text { otherwise, respond "A." }
\end{array}
$$

Besides perceptual and criterial noise, other suboptimalities might exist. For example, suboptimalities might exist in category distribution knowledge. Continuing with our medical diagnosis example, the doctor may not know the distribution parameters that describe the relation between medical test $X$ and the two diseases (i.e., $\mu_{A}, \mu_{B}$, $\sigma_{A}^{2}$, and $\sigma_{B}^{2}$ ). Thus, instead of using the optimal decision function $l_{0}$, the observer might use a suboptimal decision function. Suboptimalities might also exist in knowledge of the costs and benefits or in the way this information is combined. For example, the utility function might not be linear, or the doctor might underestimate the true costs associated with misdiagnoses. Thus, instead of using the optimal decision criterion, the observer might use a suboptimal decision criterion.

Recently, Maddox and Bohil (1998a; Bohil \& Maddox, in press) examined performance in simple analogs of the medical decision-making problem outlined above. The focus was on an examination of categorization performance when the benefit associated with a correct response for one category was larger than the benefit associated with a correct response for the other category. In all cases, the cost associated with an incorrect response was zero. Simple two-dimensional stimuli were utilized, and observers completed a large number of sessions to ensure performance had reached asymptote. The analyses were conducted at the level of the individual observer and centered on the application of three decision bound models, each of which made a different assumption regarding sensitivity to the benefit manipulation. The optimal decision bound (OPT) model (Equation 4) assumed that the observer had accurate knowledge of the category benefits and thus used the optimal decision criterion, $\beta_{\mathrm{o}}$ (albeit in the presence of criterial noise), in an attempt to maximize long-run reward. The payoff neglect (PON) model assumed that the observer ignored the true category benefits and instead behaved as if the benefits were equal 


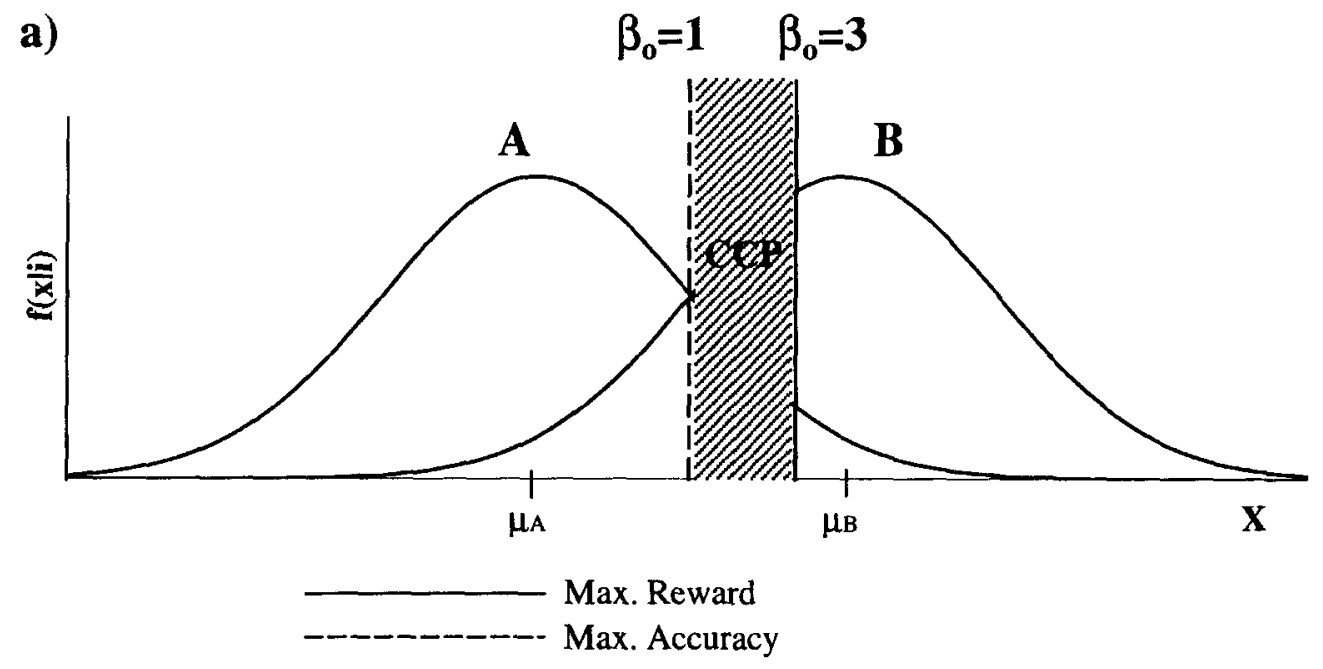

b)

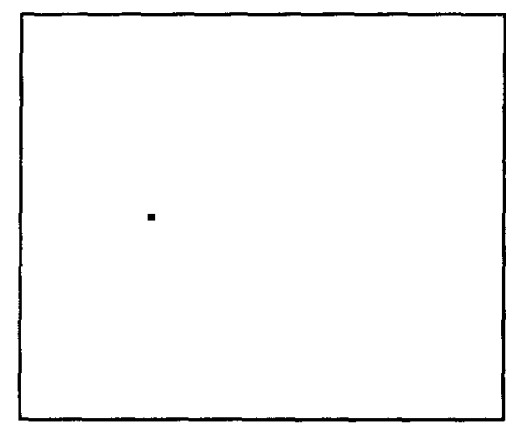

A

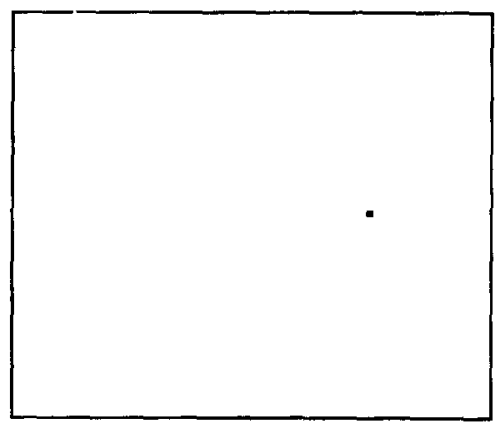

B

Figure 1. (a) Decision criteria for the classifier that maximizes long-run reward $\left(\beta_{0}=3\right)$ and long-run accuracy $\left(\beta_{0}=1\right)$ in the experimental conditions of the present experiment. The shaded area denotes the region for which conservative cutoff placement results. (b) Representative stimuli from each category.

(i.e., assumed $\beta=1$ ). An interesting facet of cost-benefit manipulations is that they require the observer to trade off accuracy maximization (which is always driven by the equal likelihood criterion) and reward maximization. Thus, another way to think of the PON model is as an accuracy-maximization model. Within the framework of decision theory, the PON is equivalent to a situation in which the utility function is equal to one for correct responses and is equal to zero for incorrect responses. We elaborate on this issue in the Discussion section. (Throughout this article, we will use the term payoff to denote the global effects of a cost-benefit manipulation. For example, if the cost-benefit structure is such that the observer is biased toward response " $A$," then we refer to category $A$ as the high-payoff category. Thus, if the observer is ignoring the cost-benefit structure, then he/she is defined as showing payoff neglect.) The suboptimal payoff (SO) model assumed that the observer was sensitive to the difference between category benefits but used a suboptimal decision criterion. (There are several possible interpretations of this model within the framework of decision theory. One possibility is that the utility function is piecewise linear, but the slope and intercept differs for costs and benefits. Another possibility is that the utility function is nonlinear.) In this model, the value of $\beta$ was estimated from the data. Because $\beta$ was a free parameter in the SO payoff model but was fixed a priori in the OPT and PON models, the OPT and PON models are "nested" under the SO payoff model. The models are nested because the OPT and PON models can be derived from the SO payoff model by setting the $\beta$ parameter to a fixed value. Likelihood ratio tests (Ashby, 1992; Wickens, 1982) were used to identify the most parsimonious model for each observer. (Single observer analyses were performed because Maddox, 1999, showed that averaging can alter the structure of the data in such a way that the correct model of individual performance can provide a poor account of averaged performance.) The most parsimonious model is defined as the model with the fewest number of free parameters that is not "significantly" improved on by a more general model. The same procedures were used in the present study. 
To summarize, in Maddox and Bohil (1998a), all of the observers showed some sensitivity to the category benefit difference (i.e., the PON model was rejected for every observer), but few used the optimal decision criterion. An examination of the $\beta$ estimates from the SO payoff model suggested that observers tended to use a decision criterion that was more conservative than the optimal decision criterion. For example, when the benefits were such that $\beta_{\mathrm{o}}=3$, observers tended to use a $\beta$ between 1 and 3 . This is termed conservative cutoff placement and is depicted in Figure la by the shaded area. This is a common finding in the literature (e.g., Busemeyer \& Myung, 1992; Green \& Swets, 1966; Healy \& Kubovy, 1981).

\section{Cost and Benefit Manipulations in Categorization and Decision Making}

Categorization studies that manipulate the category benefits while setting the category costs to zero indicate that observers tend to show conservative cutoff placement. Unfortunately, with one exception (Busemeyer \& Myung, 1992), no studies have examined the effects of nonzero costs on human categorization performance. This is an important issue because a large body of decision-making research suggests that observers are not only sensitive to cost-benefit manipulations but also that observers tend to place more weight on costs than on benefits (e.g., Kahneman \& Tversky, 1979; see also Higgins, 1987). As stated earlier, most of these studies used word problems in which the relevant information was presented explicitly. One goal of the present study was to formalize this DWH and to test it in a traditional categorization task in which the relevant information is learned implicitly through experience with the category members. Several instantiations of the DWH are possible, but we thought that a reasonable approach was to generalize the equation for the optimal decision criterion (Equation 2). Specifically, we assumed that a decision weight, $w_{A}$, was assigned to the benefit of a correct " $A$ " response, and $1-w_{A}$ was assigned to the cost of an incorrect " $B$ " response to an exemplar from category $A$. Analogously, a decision weight, $w_{B}$, was assigned to the benefit of a correct " $\mathrm{B}$ " response, and $1-w_{B}$ was assigned to the cost of an incorrect " $A$ " response to an exemplar from category $B$. In other words,

$$
\beta_{\mathrm{DWH}}=\frac{w_{A} V_{a A}-\left(1-w_{A}\right) V_{b A}}{w_{B} V_{b B}-\left(1-w_{B}\right) V_{a B}},
$$

where $0 \leq w_{A} \leq 1$, and $0 \leq w_{B} \leq 1$. Of course, it is reasonable to suppose that $w_{A}=w_{B}$. Several comments are in order. First, when $w_{A}<.5$ and $w_{B}<.5$, the costs are being weighted more heavily than the benefits, and the DWH is supported. Second, when $w_{A}=.5$ and $w_{B}=.5$, $\beta=\beta_{0}$, and so the optimal decision criterion is a special case of the differential weighting decision criterion (cf. Equation 2 with Equation 5). Third, within the framework of decision-making theories, the differential weighting rule is a generalization of expected value theory, but it is still a special case of expected utility theory.
As an initial test of the DWH, we compared performance across a number of cost-benefit conditions for which the DWH predicted qualitatively different patterns of responding. Specifically, we constructed "equivalent" cost-benefit conditions for which the DWH predicted conservative cutoff placement in some conditions and extreme cutoff placement in other conditions. (Extreme cutoff placement results when the decision criterion is larger than the optimal value.) By "equivalent" we mean conditions for which the predictions of the optimal classifier (i.e., the optimal decision criterion and the optimal long-run reward) are identical. The details will be discussed shortly.

\section{EXPERIMENT}

The goals of the present research were threefold. First, we hoped to bridge the gap between the fields of categorization and decision making by examining several categorization problems in which the cost-benefit structure was manipulated. Second, we compared and contrasted decision criterion learning across situations for which the cost of an incorrect response was either zero or nonzero. These learning data should provide a rich database for current and future model testing. Finally, we provided an initial test of the DWH in categorization. To achieve these goals, we had observers complete several categorization problems, each with a unique cost-benefit structure. Although the costs and benefits differed across conditions, the category structures (i.e., the category means and variances), optimal decision criterion $\left(\beta_{0}=3\right)$, and $\max -$ imum (optimal) reward were held fixed across conditions. The costs and benefits and DWH predictions (whether conservative or extreme cutoff placement) for different combinations of $w_{A}$ and $w_{B}$ for each of the five experimental conditions are outlined in Figure 2.

Notice that the optimal decision criterion, $\boldsymbol{\beta}_{0}$, is equal to 3 in each condition. This can be verified by applying Equation 2 to each of the five cost-benefit structures or by examining the DWH predictions when $w_{A}=w_{B}=.5$. Notice also that each cost-benefit condition has an associated multiplicative scalar, $\alpha$. The value of $\alpha$ for each condition was selected in such a way that the maximum (optimal) reward was (approximately) equal in each condition. We thought it important to equate the maximum reward to ensure that observers were equally motivated in each experimental condition. Figure $2 \mathrm{a}$ displays the costs and benefits and DWH predictions for the zero-cost condition. This served as a control condition against which the four nonzero-cost conditions (Figures $2 b-2 e$ ) were compared. In the zero-cost condition, the DWH predicts conservative cutoff placement anytime $w_{A}<w_{B}$. Notice that the costs and benefits for the nonzero-cost conditions in Figures $2 b-2 e$ are related systematically. For example, in Figure 2b, the cost of an incorrect response was equal across both categories $(-2 \alpha)$, but the benefit of a correct " $A$ " response $(4 \alpha)$ was higher than the benefit of a correct " $B$ " response $(0 \alpha)$. The Figure $2 c$ cost 
and benefit entries are very similar to those from Figure $2 \mathrm{~b}$ except that the numerical values in each column (excluding the sign) were switched. This leads to an important change in the predictions from the DWH. Specifically, when costs are weighted more heavily than benefits (i.e., when $w_{A}<.5$, and $w_{B}<.5$ ), conservative cutoff placement is predicted in the condition shown in Figure $2 b$, but extreme cutoff placement is predicted in the condition shown in Figure 2c. Figure $2 \mathrm{~d}$ is similar to Figure $2 b$ except that the numerical values in the first column (excluding the sign) were switched. Similarly, Figure $2 \mathrm{e}$ is like Figure $2 \mathrm{~b}$, except that the numerical values in the second column (excluding the sign) were switched. For Figure 2d, conservative cutoff placement results when the cost of an incorrect response to category $A$ is weighted less heavily than the benefit of a correct "A" response and when the costs of an incorrect response to category $B$ is weighted more heavily than the benefit of a correct "B" response (i.e., when $w_{A}>.5$, and $w_{B}<.5$ ). The opposite pattern holds in Figure 2e (i.e., conservative cutoff placement results when $w_{A}<.5$, and $w_{B}>$ .5). A comparison of performance across these four conditions will provide a test of the DWH and will allow us to examine how the different cost-benefit structures influence performance. If the DWH is correct, and observers weight costs more heavily than benefits, then conservative cutoff placement should be observed in some conditions, and extreme cutoff placement should be observed in other conditions.

A reasonable approach, and one we have taken in the past (Maddox, 1995; Maddox \& Bohil, 1998a, Experiment 1; Maddox \& Bohil, 1998b), is to utilize a betweenobserver design, apply the models to the individual observer data, and make comparisons across conditions. This approach would allow us to determine whether observers respond optimally, respond suboptimally, or show payoff neglect. This approach also allows us to test the DWH by examining the $\beta$ estimates from the SO payoff model. More recently, though, we have adopted a within-observer approach. This approach has several advantages. First, it minimizes between-group variability, which increases statistical power. Second, it allows us to test all of the hypotheses described above and to test a number of other hypotheses about possible relations among the observer's decision criteria across experimental conditions. This goal is achieved by developing nested decision bound models, each of which is applied to the data from all five experimental conditions simultaneously from a single observer. Each model instantiates a different set of hypotheses about the relations among the observer's decision criteria in each condition. For example, suppose we apply the OPT, SO payoff, and PON decision bound models separately to each experimental condition for a single observer, and we find conservative cutoff placement in each condition. This is an interesting finding in its own right, but it would also be useful to determine whether the "conservative" decision criterion is identical in each condition (i.e., is unaffected by the presence of nonzero costs) or is different for zero- and nonzero-cost conditions. It is straightforward to develop models to test these and other hypotheses at the level of the individual observer. Finally, a within-observer design allows us to reduce the number of free parameters. For example, separate fits of the five experimental conditions with the decision bound models would require five criterial noise parameters, whereas simultaneous fits can be obtained in which the criterial noise is assumed to be constant across all five conditions (an assumption that is reasonable in the present case). In the present study, we used both approaches. First, we modeled the data from each condition separately (separate model fits); we then applied a series of models simultaneously to the data from all five experimental conditions (simultaneous model fits). The procedures for the separate fits have already been outlined. We detail the simultaneous model fit procedures in the Results and Theoretical Analysis section.

All of the models tested in this study assume that the observer had knowledge of the category structures and used the optimal decision function [i.e., $l\left(x_{p i}\right)=l_{0}\left(x_{p i}\right)$ ]. This was an important assumption because we were interested in studying observers' sensitivity to cost and benefit manipulations and not potential suboptimalities in category distribution knowledge. To ensure that this was a reasonable assumption, the first session of the experiment was a baseline condition in which no cost-benefit manipulation was present. In addition, all observers completed a minimum of 60 baseline trials at the beginning of each of the five experimental conditions to ensure accurate knowledge of the category structures and to minimize any within-observer carryover effects from one experimental condition to the next. If the observer obtained a predetermined performance criterion of $84 \%$ (only $2 \%$ below optimal) during the initial 60 baseline trials, he/she was allowed to begin the experimental trials. If the performance criterion was not met, the observer continued receiving baseline trials until the performance criterion was reached.

\section{Observers \\ Eight observers were solicited from the University of Texas com- munity. All observers claimed to have $20 / 20$ vision or vision cor- rected to $20 / 20$. The observers were paid on the basis of their day- to-day performance in the task.}

\section{Stimuli and Stimulus Generation}

The stimulus was a horizontally varying dot that was presented within a $500 \times 500$ pixel square that was centered on a $1,024 \times 768$ resolution computer screen. The vertical position of the dot remained unchanged, and the dot was centered vertically on the screen. There were two categories, $A$ and $B$, each defined by a specific univariate normal distribution (Ashby \& Gott, 1988). The category $A$ and category $B$ means were 45 pixels to the left and right of the center of the square, respectively, and the standard deviation for each category was 42 pixels. A representative stimulus from each category is depicted in Figure Ib. The category means and standard deviations resulted in a category level $d^{\prime}$ of 2.155 . This values was chosen because previous research suggests that a category level $d^{\prime}$ in the range of 2-3 yields a fairly steep function relating the objective reward to the decision criterion (this is called the objective reward function; von Winterfeldt \& Edwards, 1982). Some have argued 
a)
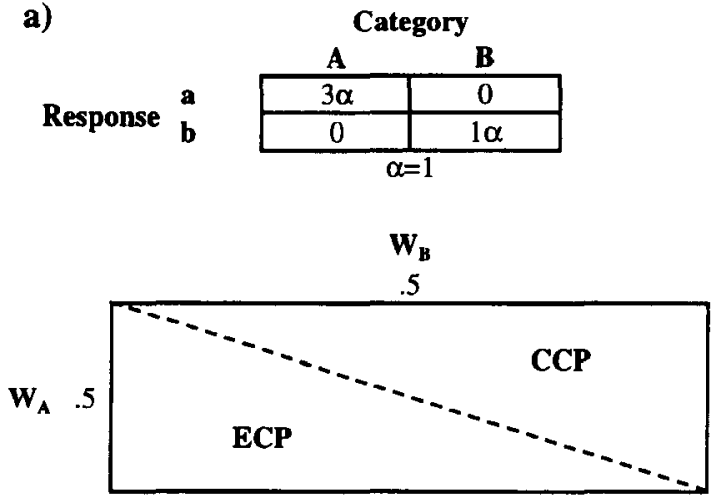

CCP: $\mathrm{W}_{\mathrm{A}}<\mathrm{W}_{\mathrm{B}}$

b)
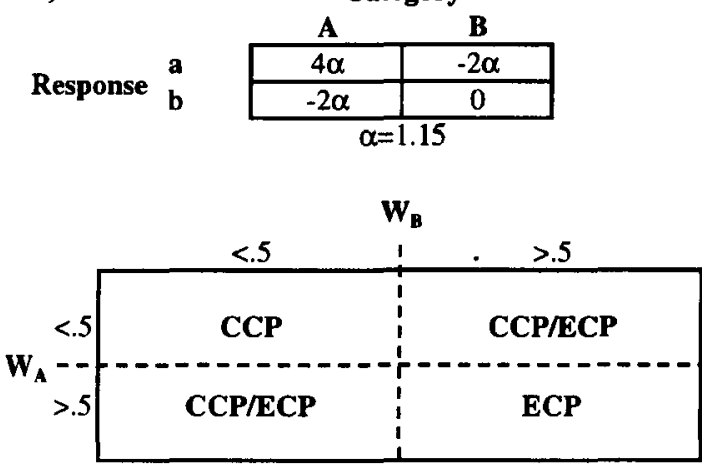

CCP: $W_{A}<.5 ; W_{B}<.5$

d)
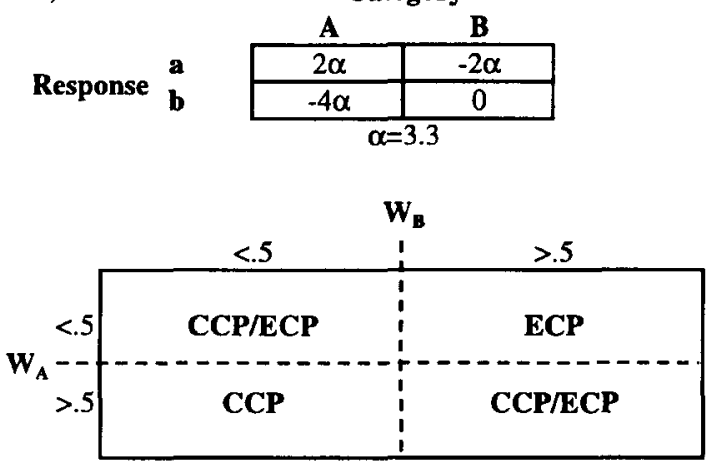

CCP: $\mathrm{w}_{\mathrm{A}}>.5 ; \mathrm{w}_{\mathrm{B}}<.5$ c)
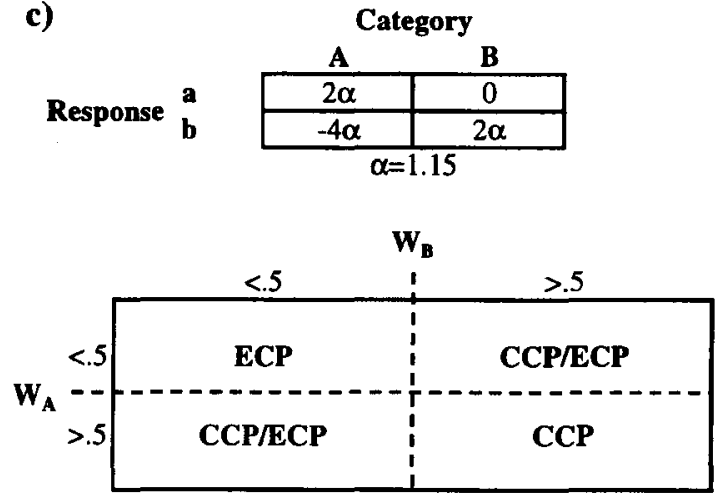

CCP: $W_{A}>.5 ; W_{B}>.5$

e)
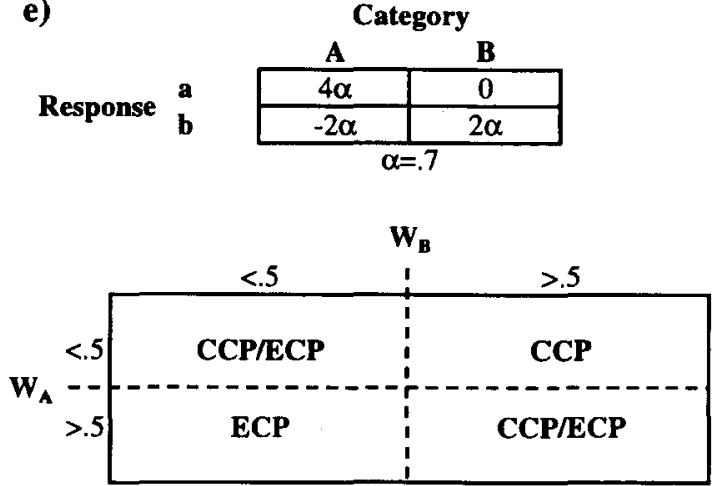

CCP: $W_{A}<.5 ; W_{B}>.5$

Figure 2. Cost-benefit structures and differential weighting hypothesis predictions for various combinations of the weight values, $w_{A}$ and $w_{B}$, for the zero-cost condition (a) and for the four nonzero-cost conditions (b-e).

that shallow objective reward functions may adversely affect the optimality of observers' performance (Bohil \& Maddox, in press; Busemeyer \& Myung, 1992; Maddox \& Bohil, 1998a). The goal of the present research was to use a very steep objective reward function to improve the observers' chances of responding optimally.
Prior to the experiment, a set of 60 stimuli was sampled randomly from each category distribution, yielding a total of 120 unique stimuli. In each block of 120 trials, every stimulus was presented once. Each session consisted of five blocks of trials in which the presentation order was randomized within each block. The first four 
blocks denoted the training phase. Trial-by-trial feedback was provided during the training phase (see details below). The final block of trials comprised the transfer phase. No feedback was provided during the transfer phase.

In the baseline condition, the cost of an incorrect response was zero (i.e., $V_{a B}=V_{b A}=0$ ), and the benefit of a correct response was 2 points (i.e., $V_{a A}=V_{b B}=2$ ). The costs and benefits associated with "A" and "B" responses in each of the five experimental conditions are displayed in Figure 2 . In all conditions, each point earned the observer $\$ 0.005$. The point totals predicted by the optimal classifier (i.e., the classifier that maximizes long-run reward) for a block of 120 trials were 206 for the baseline condition and 213,213,213, 216 , and 216 for the five conditions shown in Figures $2 \mathrm{a}-2 \mathrm{e}$, respectively. The optimal accuracy was $86 \%$ in the baseline condition and was $83 \%$ in all five experimental conditions. In the baseline condition, $\beta_{0}=1$; in all experimental conditions, $\beta_{0}=3$.

\section{Procedure}

The observers were told that perfect performance was impossible. However, an optimal level of performance was specified as a goal (in the form of desired point totals). The observers were informed that the dot would vary only in horizontal position and that their goal was to maximize points in each session. They were informed that these point totals would be converted into monetary values that they would receive at the end of the experiment. On each day of the experiment, the observers were given a $3 \times 5$ in. note card depicting the cost-benefit structure in effect for that day's condition. The observers were instructed to maximize points and not worry about speed of responding. A typical trial proceeded as follows. A stimulus was presented on the screen and remained until a response was made. The observer's task was to classify the presented stimulus as a member of category $A$ or category $B$ by pressing the appropriate button (either the " $A$ " or the "B"). During the training phase, the observer's response was followed by $750 \mathrm{msec}$ of feedback. Three lines of feedback were presented. The top line indicated the number of points the observer earned for the response. The next line indicated the potential point earnings for a correct response on each trial (i.e., if an observer responded incorrectly, this line indicated the amount that could have been earned had they chosen the correct response). The third line indicated the amount of money that the observer had accumulated up to that point in the session. The feedback was followed by a 125 -msec intertrial interval (ITI) in which the screen was blank. During the transfer phase, the observer's response was followed by an $875-\mathrm{msec}$ ITI in which the screen was blank. The observer was given periodic breaks during the training and transfer trials. At each break, the observer's accumulated point total was displayed.

During the first session, each observer completed five blocks in the baseline condition. The baseline condition was completed first to ensure that each observer had accurate knowledge of the category structures before being exposed to the cost-benefit manipulations. The five experimental conditions were completed, one session per day, on subsequent days starting with the Figure $2 a$ condition and concluding with the Figure $2 \mathrm{e}$ condition. Before each experimental session, the observer completed a minimum of 60 baseline trials. If the observer reached a criterion of $84 \%$ correct $(2 \%$ below opti$\mathrm{mal}$ ), then he/she was allowed to begin the experimental condition. If the observer did not reach criterion, he/she continued in the baseline condition until criterion was reached. Once the criterion was reached, the observer was allowed to begin the experimental condition. These baseline trials prior to each experimental condition ensured that each observer had accurate knowledge of the category structures before exposure to the cost-benefit manipulation and minimized the possibility of within-observer carryover effects from one experimental condition to the next. The first experimental condition for all observers was the zero-cost condition (Figure 2a). For half of the observers, category $A$ was the high-payoff category; for half of the observers, category $B$ was the high-payoff category. The high-payoff category then alternated between category $A$ and category $B$ across the subsequent conditions. The " $A$ " and " $B$ " response buttons were counterbalanced across observers. To simplify the analyses, all data were reorganized so that category $A$ was the highpayoff category.

\section{Results and Theoretical Analysis}

All model-based and other analyses were performed on the four blocks of training data and on the transfer data. For completeness and to facilitate future model testing, hit and false-alarm rates (where a hit was defined as a correct "A" response, and a false alarm was defined as an incorrect " $B$ " response to a category $A$ exemplar) for each observer by block and condition are presented in Appendices A and B. We begin with a discussion of baseline-condition performance and provide evidence that the observers were able to learn the category distributions and use the optimal decision rule. We then turn to a discussion of the experimental conditions.

\section{Baseline Condition}

The baseline condition was included to ensure that the observers had accurate knowledge of the category distributions prior to any cost-benefit manipulations. Two approaches were taken to determine whether we achieved this goal. First, we examined the accuracy rates, point totals, and the $\beta$ estimates from the SO payoff model across the five blocks of baseline trials. Averaged across observers, the accuracy rates, point totals, and $\beta$ estimates for each block are displayed in Figures $3 a, 3 b$, and $3 \mathrm{c}$, respectively. Although not monotonic, performance approached that of the optimal classifier across blocks and was nearly optimal during the final block of trials. Second, we fit the OPT, PON, and SO payoff models to the transfer block (Block 5). For 6 of the 8 observers, the OPT model provided the most parsimonious account of the transfer data. For the remaining 2 observers, the suboptimal model provided the most parsimonious account of the transfer data; however, the OPT model provided the most parsimonious account of the fourth block of training for these 2 observers. Restricting attention to the (averaged) SO payoff model $\beta$ estimates, they steadily decreased from 1.15 during the first block to 1.028 by the final block of trials. In addition, the (averaged) OPT model fit accounted for $95.3 \%$ of the responses during the transfer block. Finally, averaged across observers, $85.2 \%$ accuracy (optimal $=86 \%$ ) and 204.5 points (optimal $=$ 206 points) were obtained during the transfer phase. Taken together, the model-based analyses, accuracy rates, and point totals suggest that the observers learned the category distributions and used the optimal decision rule by the end of the baseline condition.

\section{Experimental Conditions}

Summary statistics and SO payoff model fits by block. Appendices A and B display the hit rates and false-alarm rates (where a hit was defined as a correct "A" response, and a false alarm was defined as an incorrect " $B$ " response to a category $A$ exemplar) for each of 
a)

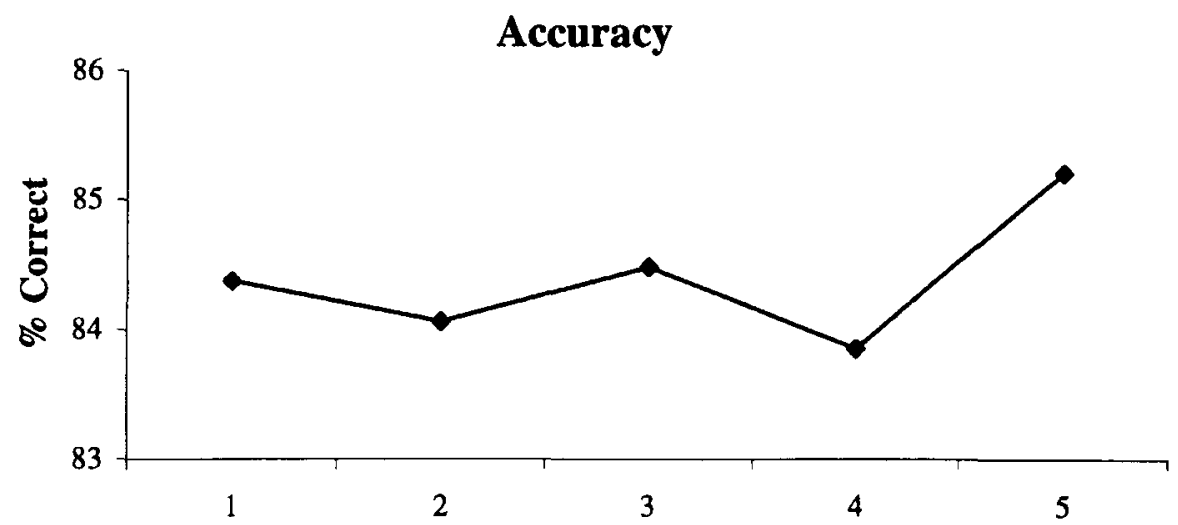

b)
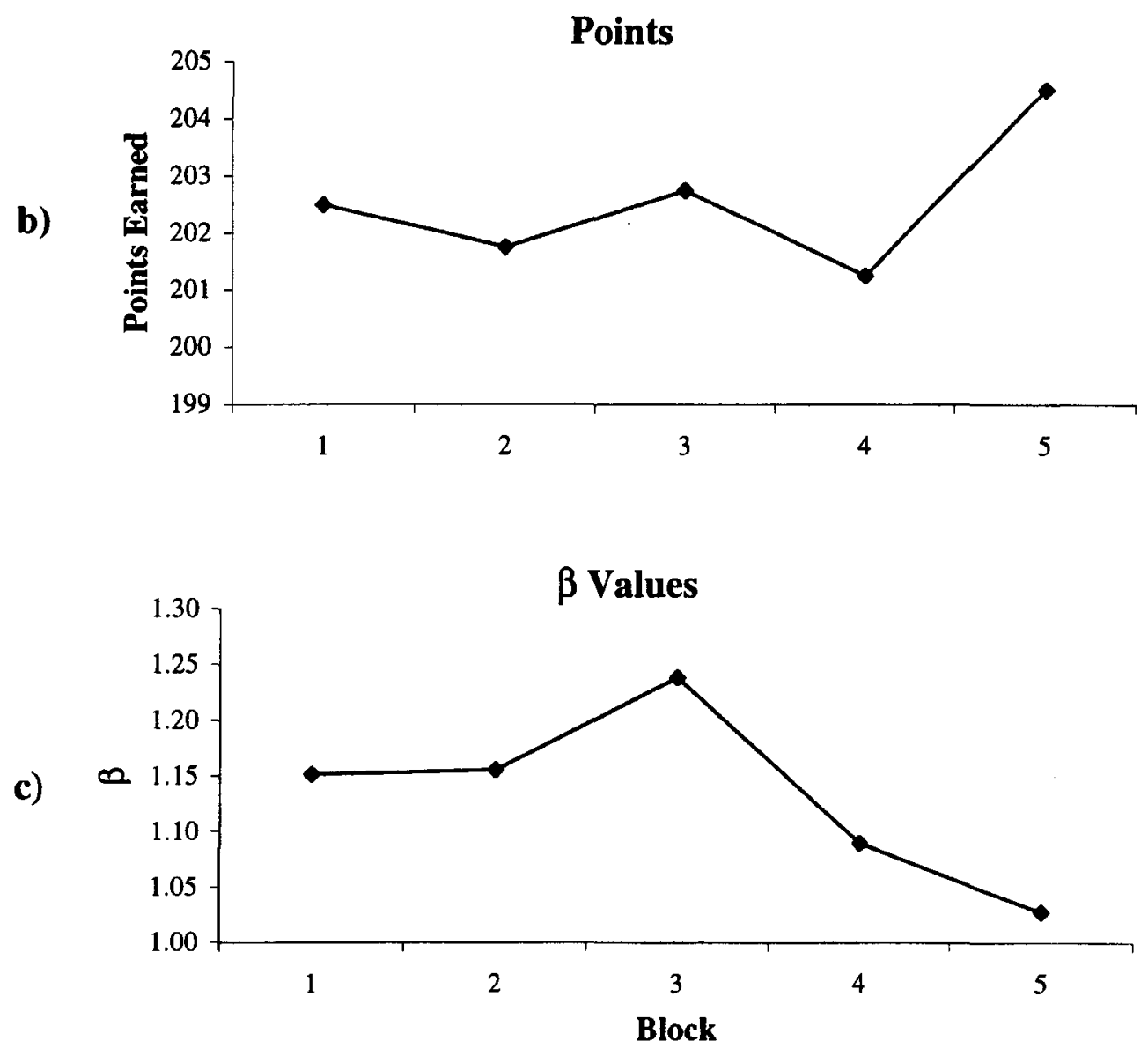

Figure 3. Accuracy rates, point totals, and SO payoff model decision criterion from the baseline condition by block averaged across observers.

the five Figure 2 conditions by observer and block. The (averaged) accuracy rates (derived from the hit and falsealarm data), point totals, and SO payoff model $\beta$ estimates are displayed in Figures $4 \mathrm{a}, 4 \mathrm{~b}$, and $4 \mathrm{c}$, respectively. (The $\beta$ value for Observer 5, Block 3, Condition $2 \mathrm{~b}$ was removed from Figure $4 \mathrm{c}$ because it was several standard deviations removed from the rest of the data.) The thick solid line denotes the Figure $2 \mathrm{a}$ zero-cost condition data.
The data averaged across the four nonzero-cost conditions are also included in each figure and are denoted by the thick broken line. This facilitates a comparison of the zero- and nonzero-cost conditions. The data are variable across blocks, but a focus on the first and last training blocks (Blocks 1 and 4 ) and the transfer block suggests several interesting findings. First, there was a small increase in the point totals across blocks, with a slight ad- 
vantage for the zero-cost condition over the (averaged) nonzero-cost condition. The true zero-cost versus nonzerocost difference is potentially larger, since the optimal point total was slightly higher in the Figures $2 \mathrm{~d}$ and $2 \mathrm{e}$ conditions - both nonzero-cost conditions. Second, accuracy showed a general decline from the first to the last training block, but then increased from the last training block to the transfer block. (Recall that the optimal classifier maximizes long-run reward; thus, when costs and benefits are manipulated, it must sacrifice accuracy to attain this goal.) In addition, during the final training block and during the transfer block, accuracy in the zerocost condition was lower than in any of the nonzero-cost conditions, suggesting that the observers were more willing to sacrifice accuracy when there were no costs associated with an incorrect response. Third, the SO payoff model $\beta$ estimates showed a general increase from the first to the last training block and were closer to the optimal value $\left(\beta_{o}=3\right)$ in the zero-cost condition. Interestingly, though, the $\beta$ value continued approaching the optimal value during the transfer block in the zero-cost condition but became less optimal (i.e., decreased toward 1) during the transfer block in the nonzero-cost conditions. Finally, there was little support for the DWH. The strongest test of the DWH requires a comparison of the $\beta$ estimates from the Figures $2 b$ and $2 c$ conditions. Specifically, if the DWH is supported, then conservative cutoff placement should result in the Figure $2 b$ condition, and extreme cutoff placement should result in the Figure 2c condition. This was not the case; conservative cutoff placement was prevalent in both conditions. Although these data do not support a strong version of the DWH, a weaker version of the DWH can be formulated. Whereas the strong version requires extreme cutoff placement in Figure $2 c$ and conservative cutoff placement in Figure $2 b$, a weaker version would require only that the decision criterion be larger in Figure 2c than in Figure $2 \mathrm{~b}$. This version received some support. During the transfer block, the weak version of the DWH was supported for 5 of the 8 observers, but it was supported for only 2 of the 8 observers during the final training block.

At this stage, a few comments are in order regarding the qualitative shift in performance across the training and transfer blocks. Within the framework of the SO payoff model, there are two factors that affect accuracy. One is the placement of the decision criterion $\beta$. In the present study, as $\beta$ approached the optimal value, accuracy should have decreased. Thus, it is not surprising that accuracy decreased during training while the $\beta$ estimate increased. The second is the trial-by-trial variability in the placement of the decision criterion (criterial noise). In general, the larger the criterial noise (for a fixed decision criterion), the lower the accuracy. The criterial noise estimates from the SO payoff model showed a moderate (although nonmonotonic) decline across the training blocks, followed by a sharp decline during the transfer block. ${ }^{3}$ The observers were instructed to use a fixed decision criterion during the transfer block, and the noise estimates suggest that the observers followed this instruction. One possibility is that the increase in accuracy during the transfer block in the zero-cost condition was due to the reduction in criterial noise and not to a decrease in the $\beta$ value, since the $\beta$ estimates increased. In the nonzero-cost condition, on the other hand, the increase in accuracy was likely due to both a decrease in criterial noise and a decrease in the $\beta$ value associated with a greater emphasis on accuracy. Although speculative, it appears that the withdrawal of feedback (during the transfer trials) led to a greater emphasis on accuracy when nonzero costs were incurred but led to a continued emphasis on reward when the cost of an incorrect response was zero. Clearly, further research is needed to test this speculative hypothesis. Even so, the remaining model-based analyses were performed on the final training block and on the transfer block.

Separate model fits of the final training block and the transfer block. Tables 1A and 1B present the most parsimonious model, percent of responses accounted for by the most parsimonious model, and the $\beta$ estimates from the most parsimonious model by observer and condition for the separate model fits. Table $1 \mathrm{~A}$ presents the data for the final training block, and Table $1 \mathrm{~B}$ presents the data for the transfer block. Several interesting results emerge. First, there was little evidence of extreme cutoff placement. In fact, in only 6 of the 40 cases ( 8 observers $\times 5$ cost-benefit structures) during the final block of training and in only 2 of 40 cases during transfer was extreme cutoff placement observed, and 6 of these were shown for the same observer (Observer 6). Second, the remaining cases were fairly evenly distributed between optimal cutoff placement (final block of training, 14 of 40; transfer, 11 of 40 ), conservative cutoff placement (final block of training, 10 of 40; transfer, 14 of 40), and payoff neglect (final block of training, 10 of 40 ; transfer, 13 of 40 ). Third, the average $\beta$ value was closer to the optimal value in the zero-cost condition than in the nonzerocost conditions during the final block of training and during transfer. Finally, on the basis of the $\beta$ values from the most parsimonious model, we again find some support for the weaker version of the DWH, but not for the stronger version. Specifically, the averaged $\beta$ values are larger in the Figure $2 \mathrm{c}$ condition than in the Figure $2 \mathrm{~b}$ condition, but only during the transfer block. During the final block of training, the opposite holds. We turn now to the simultaneous model fits.

Simultaneous model fits of the transfer data for all experimental conditions. The nested structure of the simultaneous fit models is outlined in Figure 5. The arrows point to a more general model. Two one-parameter models were tested. The optimal decision bound (OPT) model assumes that the observer's decision criterion was optimal in each condition, and the observer attempted to maximize long-run reward. The only free parameter was the noise parameter. The payoff neglect ( $\mathrm{PON}$ ) model assumes that the observer was completely insensitive to, and neglected, the payoff differences, which is equivalent to maximizing categorization accuracy. Again, the only free parameter was the noise parameter. Two twoparameter models were tested. The suboptimal (SO) 
a)

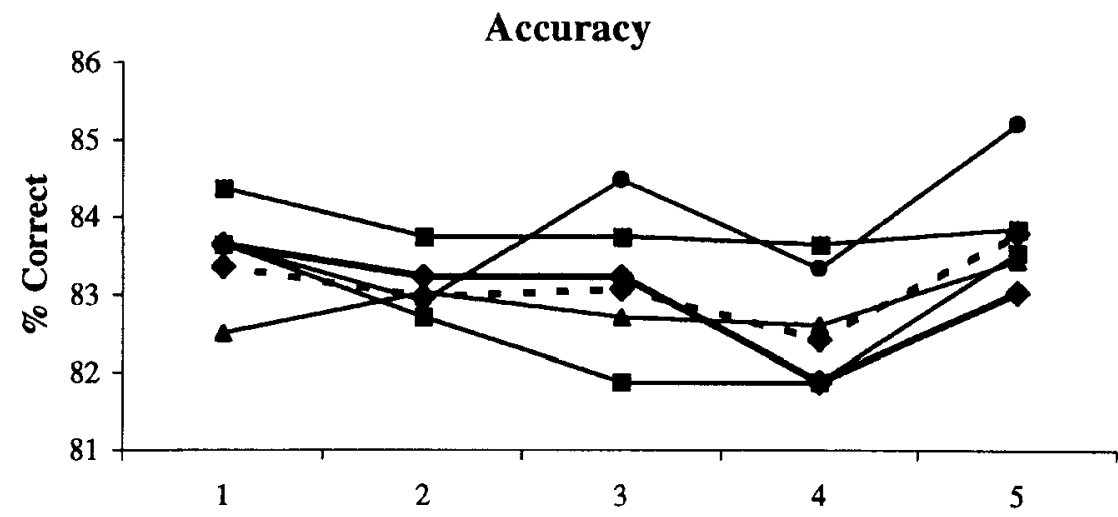

b)
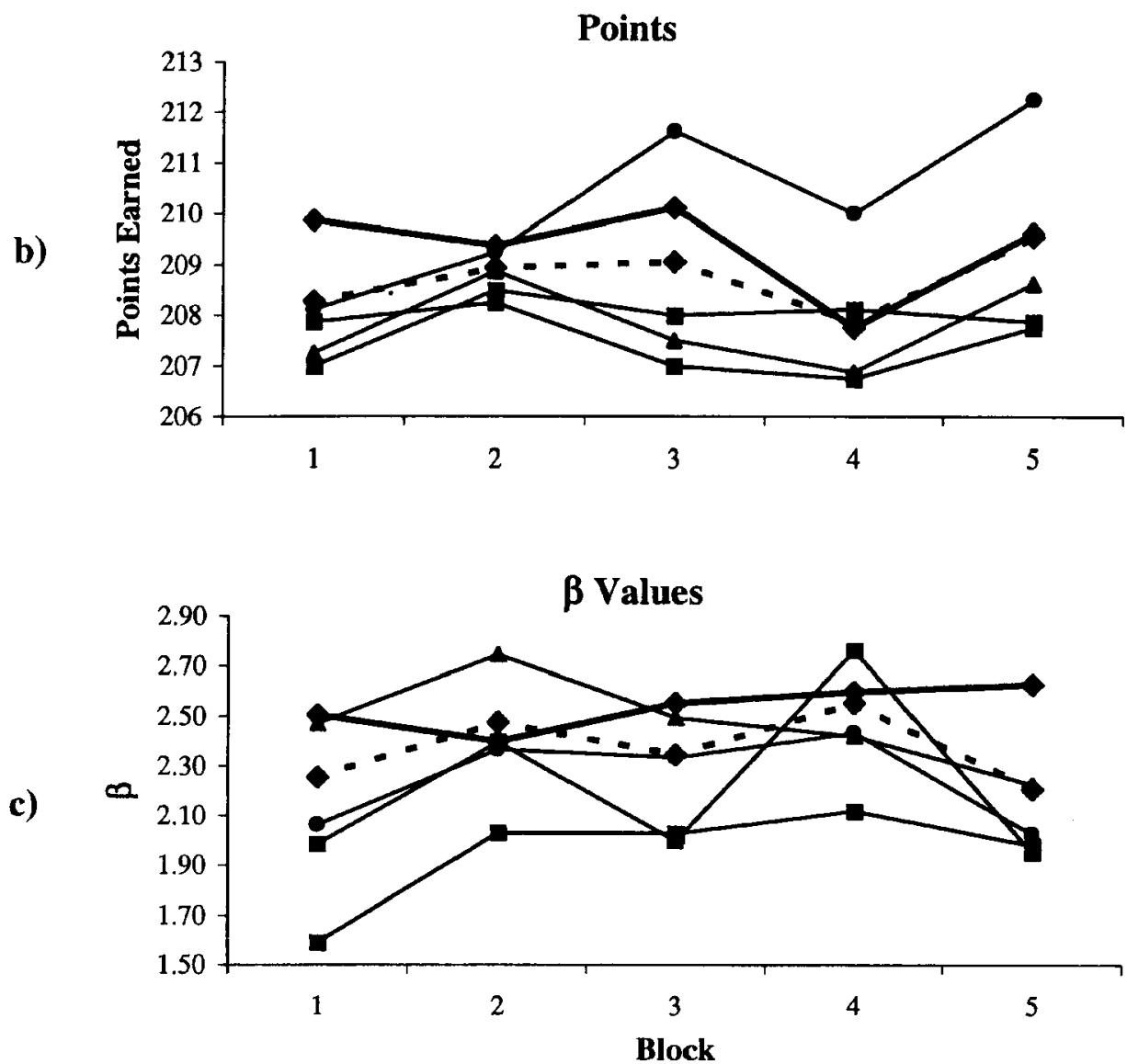

$$
\neg-2 \mathrm{a} \rightarrow-2 \mathrm{~b} \rightarrow 2 \mathrm{c} \rightarrow-2 \mathrm{~d} \rightarrow-2 \mathrm{e}-\bullet-\text { average }
$$

Figure 4. Accuracy rates, point totals, and SO payoff model decision criterion from the five experimental conditions (as well as the average of the four nonzero-cost conditions) by block averaged across observers.

payoff model assumes that the observer was sensitive to the cost-benefit manipulation but used a suboptimal decision criterion that was identical in all experimental conditions. This model instantiates the hypothesis that performance is unaffected by the presence (or absence) of nonzero costs. The suboptimal zero-cost, payoff neglect nonzero-cost (SO Zero, PON Nonzero) model assumes that the observer was sensitive to the cost-benefit ma- 
Table 1A

Most Parsimonious Model, Percent of Responses Accounted for by Most Parsimonious Model, and $\beta$ Estimate From the Most Parsimonious Model by Observer and Condition for the Final Training Block

\begin{tabular}{|c|c|c|c|c|}
\hline Observer & $\begin{array}{c}\text { Condition } \\
\text { (Figure) }\end{array}$ & $\begin{array}{c}\text { Most } \\
\text { Parsimonious } \\
\text { Model } \\
\end{array}$ & $\begin{array}{c}\% \text { of Responses } \\
\text { Accounted For } \\
\end{array}$ & $\beta$ Values \\
\hline 1 & $\begin{array}{l}2 \mathrm{a} \\
2 \mathrm{~b} \\
2 \mathrm{c} \\
2 \mathrm{~d} \\
2 \mathrm{e}\end{array}$ & $\begin{array}{l}\text { SO Payoff } \\
\text { SO Payoff } \\
\text { PON } \\
\text { SO Payoff } \\
\text { SO Payoff }\end{array}$ & $\begin{array}{l}97.50 \\
98.33 \\
93.33 \\
98.33 \\
97.50\end{array}$ & $\begin{array}{l}2.00 \\
1.64 \\
1.00 \\
1.81 \\
0.68\end{array}$ \\
\hline 2 & $\begin{array}{l}2 a \\
2 b \\
2 c \\
2 d \\
2 e\end{array}$ & $\begin{array}{l}\text { OPT } \\
\text { PON } \\
\text { SO Payoff } \\
\text { OPT } \\
\text { SO Payoff }\end{array}$ & $\begin{array}{l}92.50 \\
96.67 \\
95.00 \\
96.67 \\
95.83\end{array}$ & $\begin{array}{l}3.00 \\
1.00 \\
1.97 \\
3.00 \\
1.53\end{array}$ \\
\hline 3 & $\begin{array}{l}2 \mathrm{a} \\
2 \mathrm{~b} \\
2 \mathrm{c} \\
2 \mathrm{~d} \\
2 \mathrm{e}\end{array}$ & $\begin{array}{l}\text { PON } \\
\text { OPT } \\
\text { PON } \\
\text { SO Payoff } \\
\text { PON }\end{array}$ & $\begin{array}{l}90.00 \\
91.67 \\
94.17 \\
92.50 \\
87.50\end{array}$ & $\begin{array}{l}1.00 \\
3.00 \\
1.00 \\
1.72 \\
1.00\end{array}$ \\
\hline 4 & $\begin{array}{l}2 \mathrm{a} \\
2 \mathrm{~b} \\
2 \mathrm{c} \\
2 \mathrm{~d} \\
2 \mathrm{e}\end{array}$ & $\begin{array}{l}\text { OPT } \\
\text { PON } \\
\text { PON } \\
\text { OPT } \\
\text { PON }\end{array}$ & $\begin{array}{l}92.50 \\
87.50 \\
95.00 \\
91.67 \\
91.67\end{array}$ & $\begin{array}{l}3.00 \\
1.00 \\
1.00 \\
3.00 \\
1.00\end{array}$ \\
\hline 5 & $\begin{array}{l}2 \mathrm{a} \\
2 \mathrm{~b} \\
2 \mathrm{c} \\
2 \mathrm{~d} \\
2 \mathrm{e}\end{array}$ & $\begin{array}{l}\text { PON } \\
\text { SO Payoff } \\
\text { SO Payoff } \\
\text { PON } \\
\text { SO Payoff }\end{array}$ & $\begin{array}{l}85.00 \\
95.83 \\
97.50 \\
95.83 \\
99.17\end{array}$ & $\begin{array}{l}1.00 \\
1.66 \\
1.51 \\
1.00 \\
1.46\end{array}$ \\
\hline 6 & $\begin{array}{l}2 a \\
2 b \\
2 c \\
2 d \\
2 e\end{array}$ & $\begin{array}{l}\text { SO Payoff } \\
\text { OPT } \\
\text { SO Payoff } \\
\text { SO Payoff } \\
\text { SO Payoff }\end{array}$ & $\begin{array}{l}94.17 \\
94.17 \\
94.17 \\
99.17 \\
94.17\end{array}$ & $\begin{array}{l}5.60 \\
3.00 \\
4.35 \\
4.66 \\
4.66\end{array}$ \\
\hline 7 & $\begin{array}{l}2 \mathrm{a} \\
2 \mathrm{~b} \\
2 \mathrm{c} \\
2 \mathrm{~d} \\
2 \mathrm{e}\end{array}$ & $\begin{array}{l}\text { OPT } \\
\text { SO Payoff } \\
\text { SO Payoff } \\
\text { OPT } \\
\text { OPT }\end{array}$ & $\begin{array}{l}95.00 \\
88.33 \\
87.50 \\
90.83 \\
96.67\end{array}$ & $\begin{array}{l}3.00 \\
7.06 \\
5.88 \\
3.00 \\
3.00\end{array}$ \\
\hline 8 & $\begin{array}{l}2 \mathrm{a} \\
2 \mathrm{~b} \\
2 \mathrm{c} \\
2 \mathrm{~d} \\
2 \mathrm{e}\end{array}$ & $\begin{array}{l}\text { OPT } \\
\text { OPT } \\
\text { OPT } \\
\text { OPT } \\
\text { OPT }\end{array}$ & $\begin{array}{l}91.67 \\
94.17 \\
96.67 \\
95.83 \\
98.33\end{array}$ & $\begin{array}{l}3.00 \\
3.00 \\
3.00 \\
3.00 \\
3.00\end{array}$ \\
\hline Average & $\begin{array}{l}2 \mathrm{a} \\
2 \mathrm{~b} \\
2 \mathrm{c} \\
2 \mathrm{~d} \\
2 \mathrm{e}\end{array}$ & & $\begin{array}{l}92.29 \\
93.33 \\
94.17 \\
95.10 \\
95.10\end{array}$ & $\begin{array}{l}2.70 \\
2.67 \\
2.46 \\
2.65 \\
2.04\end{array}$ \\
\hline
\end{tabular}

nipulation when the costs were zero but showed payoff neglect when the costs were nonzero. The idea here is that the presence of nonzero costs leads the observer to maximize accuracy and sacrifice reward. One three-parameter model was tested. The suboptimal zero-cost, suboptimal nonzero-cost (SO Zero, SO Nonzero) model assumes that the observer was sensitive to the cost-benefit manipulation but allows the zero-cost decision criterion to be different from the nonzero-cost decision criterion, all of which are assumed to be equal. This model instantiates the hypothesis that nonzero costs have a different effect on decision criterion placement than zero costs. However, this model makes the simple assumption that the presence of any nonzero cost, regardless of its magnitude, leads to the same decision criterion. Three four-parameter models were tested. Each of these models generalizes the SO Zero, SO Nonzero model by assuming that one pair of nonzero-cost conditions yields one decision criterion and that the other pair of nonzero-cost conditions yields a different decision criterion. We will refer to these as the

\section{Table 1 B}

Most Parsimonious Model, Percent of Responses Accounted for by Most Parsimonious Model, and $\beta$ Estimate From the Most Parsimonious Model by Observer and Condition for the Transfer Block

\begin{tabular}{|c|c|c|c|c|}
\hline Observer & $\begin{array}{c}\text { Condition } \\
\text { (Figure) }\end{array}$ & $\begin{array}{c}\text { Most } \\
\text { Parsimonious } \\
\text { Model } \\
\end{array}$ & $\begin{array}{c}\% \text { of Responses } \\
\text { Accounted For }\end{array}$ & $\beta$ Values \\
\hline 1 & $\begin{array}{l}2 \mathrm{a} \\
2 \mathrm{~b} \\
2 \mathrm{c} \\
2 \mathrm{~d} \\
2 \mathrm{e}\end{array}$ & $\begin{array}{l}\text { SO Payoff } \\
\text { PON } \\
\text { SO Payoff } \\
\text { SO Payoff } \\
\text { PON }\end{array}$ & $\begin{array}{r}100.00 \\
99.17 \\
95.00 \\
95.83 \\
97.50\end{array}$ & $\begin{array}{l}1.54 \\
1.00 \\
2.19 \\
1.82 \\
1.00\end{array}$ \\
\hline 2 & $\begin{array}{l}2 \mathrm{a} \\
2 \mathrm{~b} \\
2 \mathrm{c} \\
2 \mathrm{~d} \\
2 \mathrm{e}\end{array}$ & $\begin{array}{l}\text { PON } \\
\text { SO Payoff } \\
\text { SO Payoff } \\
\text { SO Payoff } \\
\text { SO Payoff }\end{array}$ & $\begin{array}{l}95.00 \\
98.33 \\
98.33 \\
95.00 \\
96.67\end{array}$ & $\begin{array}{l}1.00 \\
1.58 \\
1.97 \\
1.99 \\
1.83\end{array}$ \\
\hline 3 & $\begin{array}{l}2 \mathrm{a} \\
2 \mathrm{~b} \\
2 \mathrm{c} \\
2 \mathrm{~d} \\
2 \mathrm{e}\end{array}$ & $\begin{array}{l}\text { SO Payoff } \\
\text { PON } \\
\text { PON } \\
\text { PON } \\
\text { PON }\end{array}$ & $\begin{array}{l}95.83 \\
90.83 \\
95.00 \\
95.00 \\
95.00\end{array}$ & $\begin{array}{l}2.09 \\
1.00 \\
1.00 \\
1.00 \\
1.00\end{array}$ \\
\hline 4 & $\begin{array}{l}2 a \\
2 b \\
2 c \\
2 d \\
2 e\end{array}$ & $\begin{array}{l}\text { SO Payoff } \\
\text { PON } \\
\text { PON } \\
\text { SO Payoff } \\
\text { PON }\end{array}$ & $\begin{array}{l}92.50 \\
82.50 \\
89.17 \\
88.33 \\
92.50\end{array}$ & $\begin{array}{l}1.75 \\
1.00 \\
1.00 \\
1.80 \\
1.00\end{array}$ \\
\hline 5 & $\begin{array}{l}2 a \\
2 b \\
2 c \\
2 d \\
2 e\end{array}$ & $\begin{array}{l}\text { PON } \\
\text { SO Payoff } \\
\text { SO Payoff } \\
\text { PON } \\
\text { PON }\end{array}$ & $\begin{array}{l}95.00 \\
97.50 \\
96.67 \\
94.17 \\
97.50\end{array}$ & $\begin{array}{l}1.00 \\
1.27 \\
1.63 \\
1.00 \\
1.00\end{array}$ \\
\hline 6 & $\begin{array}{l}2 \mathrm{a} \\
2 \mathrm{~b} \\
2 \mathrm{c} \\
2 \mathrm{~d} \\
2 \mathrm{e}\end{array}$ & $\begin{array}{l}\text { SO Payoff } \\
\text { OPT } \\
\text { OPT } \\
\text { OPT } \\
\text { SO Payoff }\end{array}$ & $\begin{array}{r}98.33 \\
95.83 \\
98.33 \\
100.00 \\
97.50\end{array}$ & $\begin{array}{l}6.65 \\
3.00 \\
3.00 \\
3.00 \\
4.16\end{array}$ \\
\hline 7 & $\begin{array}{l}2 a \\
2 b \\
2 c \\
2 d \\
2 e\end{array}$ & $\begin{array}{l}\text { OPT } \\
\text { OPT } \\
\text { OPT } \\
\text { SO Payoff } \\
\text { OPT }\end{array}$ & $\begin{array}{l}94.17 \\
97.50 \\
90.00 \\
95.83 \\
95.00\end{array}$ & $\begin{array}{l}3.00 \\
3.00 \\
3.00 \\
2.09 \\
3.00\end{array}$ \\
\hline 8 & $\begin{array}{l}2 \mathrm{a} \\
2 \mathrm{~b} \\
2 \mathrm{c} \\
2 \mathrm{~d} \\
2 \mathrm{e}\end{array}$ & $\begin{array}{l}\text { OPT } \\
\text { OPT } \\
\text { SO Payoff } \\
\text { OPT } \\
\text { OPT }\end{array}$ & $\begin{array}{l}96.67 \\
95.00 \\
98.33 \\
98.33 \\
96.67\end{array}$ & $\begin{array}{l}3.00 \\
3.00 \\
2.53 \\
3.00 \\
3.00\end{array}$ \\
\hline Average & $\begin{array}{l}2 \mathrm{a} \\
2 \mathrm{~b} \\
2 \mathrm{c} \\
2 \mathrm{~d} \\
2 \mathrm{e}\end{array}$ & & $\begin{array}{l}95.94 \\
94.58 \\
95.10 \\
95.31 \\
96.04\end{array}$ & $\begin{array}{l}2.50 \\
1.86 \\
2.04 \\
1.96 \\
2.00\end{array}$ \\
\hline
\end{tabular}


suboptimal zero-cost, suboptimal nonzero-cost differential pair models. One version of this model assumes a single decision criterion in the Figures $2 \mathrm{~b}$ and $2 \mathrm{~d}$ conditions and a different decision criterion in the Figures $2 \mathrm{c}$ and $2 \mathrm{e}$ conditions. Because this model pairs the nonzero-cost conditions that have the same cost-benefit structure for the low-payoff category (i.e., the " $B$ " column of each cost-benefit structure), we refer to this as the suboptimal zero-cost, suboptimal nonzero-cost low-payoff pairing model. A second version of this model assumes a single decision criterion in the Figures $2 \mathrm{~b}$ and $2 \mathrm{e}$ conditions and a different decision criterion in the Figures $2 c$ and $2 d$ conditions. Because this model pairs the nonzero-cost conditions that have the same cost-benefit structure for the high-payoff category (i.e., the "A" column of each cost-benefit structure), we refer to this as the suboptimal zero-cost, suboptimal nonzero-cost high-payoff pairing model. The third version of this model assumes a single decision criterion in the Figures $2 b$ and $2 c$ conditions and a different decision criterion in the Figures $2 \mathrm{~d}$ and $2 \mathrm{e}$ conditions. Because this model pairs the nonzero-cost conditions for which the low- and high-payoff cost-benefit structures are switched, we refer to this as the suboptimal zero-cost, suboptimal nonzero-cost switched payoff pairing model. Each of these four-parameter models contradicts the strong version of the DWH because each assumes the same decision criterion in conditions for which the strong version of the DWH would predict qualitatively different decision criteria (i.e., extreme cutoff placement in one case, and conservative cutoff placement in another case). One six-parameter model was tested. The general suboptimal payoff model assumes that the observer was sensitive to the cost-benefit manipulation, but this model allowed the decision criterion in each condition to differ from that in every other condition. If the strong version of the DWH is supported, then this model should provide the most parsimonious account of the data, and the resulting decision criterion estimates from each condition should be in line with those outlined in Figure 2 .

Each of the Figure 5 models was applied to the data from each individual observer. The most parsimonious model, percent of responses accounted for by the most parsimonious model, and $\beta$ estimates from the most parsimonious model by condition and observer are summarized in Tables $2 \mathrm{~A}$ and $2 \mathrm{~B}$. Table $2 \mathrm{~A}$ presents the data for the final training block, and Table $2 \mathrm{~B}$ presents the data for the transfer block. Recall that the simultaneous modeling procedure allowed us to test several hypotheses about cost-benefit knowledge that we could not test with the separate model fits and allowed us to accomplish this with fewer free parameters. However, this is an advantage only if the simultaneous modeling approach provides a nearly equivalent account of the data. We compared the overall performance of the simultaneous and separate modeling procedures by computing the percent of responses accounted for by the most parsimonious simultaneous and separate fit models. For both the final training block and the transfer block, the percents of responses accounted for were $94 \%$ or higher and never differed by more than $1 \%$ when comparing separate with simultaneous fits. Clearly, the simultaneous models provided a good, and nearly equivalent, description of the data.

Several interesting results emerge from an examination of Tables $2 \mathrm{~A}$ and $2 \mathrm{~B}$. First, 5 of the 8 observers $(\mathrm{Ob}-$ servers $1-5$ ) showed conservative cutoff placement in all five experimental conditions for both the final training block (Table 2A) and transfer block (Table 2B). Two of these observers (Observers 3 and 5 during the final training block, and Observers 4 and 5 during the transfer block) treated the zero- and nonzero-cost conditions equivalently and used the same suboptimal decision criterion in all conditions (i.e., the most parsimonious model was the SO payoff model). The remaining 3 observers used different decision criterion in the zero- and nonzerocost conditions. Second, Observer 8 used the same decision criterion in all conditions and used a decision criterion that was close to optimal. In fact, during the final training block, the optimal decision bound model provided the most parsimonious account of this observer's data. Third, Observers 6 and 7 showed a very different pattern of responding from the other 6 observers. Observer 6 showed extreme cutoff placement in all conditions but a more extreme cutoff in the zero-cost condition (Figure 2A). Perhaps this observer invoked a response bias toward the high-payoff category (see Maddox \& Bohil, 1998a, for a discussion of response biases in categorization). Observer 7's pattern of responding was unique in many ways and was quite different during the final training block and during the transfer block. Most importantly, Observer 7 is the only observer to show support for the strong version of the DWH. Specifically, during the transfer block, this observer showed extreme cutoff placement in the Figure $2 \mathrm{c}$ condition and conservative cutoff placement in the Figure $2 B$ condition. Unfortunately, the same pattern was not observed during the final training block. Finally, some support for the weak version of the DWH was again obtained. Specifically, the average $\beta$ value for the Figure $2 \mathrm{c}$ condition was larger than that for the Figure $2 \mathrm{~B}$ condition, but only during the transfer block. Even so, this was due mainly to the results of Observers 1 and 7. For the remaining observers, the $\beta$ estimates from the most parsimonious model were identical in these two conditions.

\section{Discussion}

In this paper, we report the results of an experiment that attempted to bridge the gap between categorization and decision-making research by examining human categorization performance when the costs and benefits associated with each categorization response were manipulated. The cost-benefit structures differed across conditions but were selected so that the performance of the optimal classifier (derived from the expected value rule) was identical across conditions. Each observer completed several blocks of trials with each of the cost-benefit structures. This allowed us to capture the time course of cost-benefit learning and provided a rich database for current and future model testing. One focus was to compare 
$\mathbf{l}(\mathbf{x})=\mathbf{l}_{\mathbf{0}}(\mathbf{x})$

$\sigma_{\mathrm{t}}$ constant across conditions
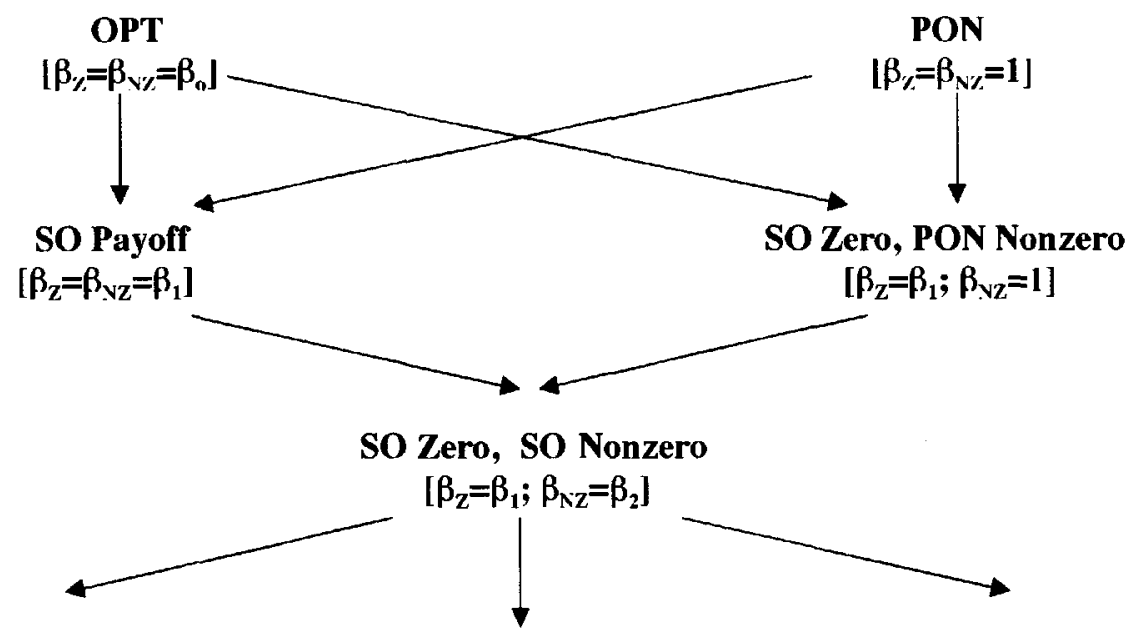

SO Zero, SO Nonzero, Low-Payoff Pairing $\left[\beta_{z}=\beta_{1}\right]$
$\left[\beta_{2 b}=\beta_{2 d}=\beta_{2}\right]$
$\left[\beta_{2 c}=\beta_{2 e}=\beta_{3}\right]$
SO Zero, SO Nonzero, High-Payoff Pairing $\left[\beta_{\mathrm{z}}=\beta_{1}\right]$ $\left[\beta_{2 \mathrm{~b}}=\beta_{2 \mathrm{e}}=\beta_{2}\right]$ $\left[\beta_{2 c}=\beta_{2 d}=\beta_{3}\right]$
SO Zero, SO Nonzero, Switched Pairing $\left[\beta_{\mathrm{z}}=\beta_{1}\right]$ $\left[\beta_{2 \mathrm{~b}}=\beta_{2 \mathrm{c}}=\beta_{2}\right]$ $\left[\beta_{2 \mathrm{~d}}=\beta_{2 \mathrm{e}}=\beta_{3}\right]$

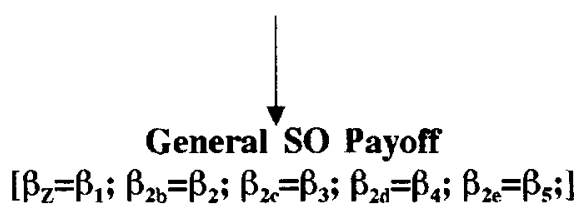

Figure 5. Nested relationship among the decision bound models applied simultaneously to the data from all five experimental conditions. The arrow points to a more general model.

performance when the cost of an incorrect response was zero versus nonzero. A second focus was to provide a test of the hypothesis that observers weight costs more heavily than benefits during categorization. This hypothesis has received some support in the decision-making literature but, to date, has not been tested in categorization.

In general, the observers showed sensitivity to the cost-benefit structures in both the zero-cost condition and the nonzero-cost conditions. As the observers gained experience with the cost-benefit structures, model-based estimates of the decision criterion and point totals increased toward the optimal values, and accuracy rates declined. The observers' performance was consistently better in the zero-cost condition than in the nonzero-cost conditions. In addition, during the transfer block, in which trial-by-trial feedback was removed, the observers' continued to show improved performance in the zerocost condition but decrements in performance in the nonzero-cost conditions. Across all conditions, the most common finding was conservative cutoff placement (the use of a decision criterion more conservative than that used by the optimal classifier). Finally, only modest sup- port was found for the differential weighting hypothesis. We now turn to a more detailed discussion of the more salient findings.

\section{Prevalence of Conservative Cutoff Placement}

Across a number of studies that focused on base-rate and/or category benefit learning, the most common finding was that observers were sensitive to the manipulation but that they tended to use a decision criterion that was more conservative than that predicted by the optimal classifier (Bohil \& Maddox, in press; Busemeyer \& Myung, 1992; Maddox \& Bohil, 1998a, 1998b). This is commonly referred to as conservative cutoff placement. The present study included several conditions in which both the costs and benefits were manipulated. Again, the most prevalent finding was conservative cutoff placement. Several explanations for conservative cutoff placement have been offered in the literature. We briefly review these and offer another explanation.

Distribution misconception hypothesis. One hypothesis is that conservative cutoff placement is caused by a systematic misconception of the shape of the under- 
Table 2A

Most Parsimonious Figure 5 Model, $\beta$ Estimates, and Percent of Responses Accounted for by Most Parsimonious Figure 5 Model for the Experimental Conditions From the Final Training Block

\begin{tabular}{|c|c|c|c|c|c|c|c|}
\hline \multirow[b]{2}{*}{ Observer } & \multirow[b]{2}{*}{ Most Parsimonious Model } & \multicolumn{5}{|c|}{$\begin{array}{c}\beta \text { Values } \\
\text { Experimental Condition }\end{array}$} & \multirow[b]{2}{*}{$\%$ Accounted For } \\
\hline & & $2 a$ & $2 b$ & $2 \mathrm{c}$ & $2 \mathrm{~d}$ & $2 \mathrm{e}$ & \\
\hline 1 & $\begin{array}{r}\text { SO Zero, SO Nonzero } \\
\text { Low-Payoff Pairing }\end{array}$ & 1.94 & 1.60 & 0.90 & 1.60 & 0.90 & 96.3 \\
\hline 2 & SO Zero, SO Nonzero & & & & & & \\
\hline & High-Payoff Pairing & 2.51 & 1.36 & 2.15 & 2.15 & 1.36 & 95.3 \\
\hline 3 & SO Payoff & 1.51 & 1.51 & 1.51 & 1.51 & 1.51 & 91.3 \\
\hline 4 & SO Zero, SO Nonzero & & & & & & \\
\hline & Low-Payoff Pairing & 2.26 & 1.84 & 1.00 & 1.84 & 1.00 & 91.8 \\
\hline 5 & SO Payoff & 1.43 & 1.43 & 1.43 & 1.43 & 1.43 & 95.3 \\
\hline 6 & SO Zero, SO Nonzero & 5.63 & 4.15 & 4.15 & 4.15 & 4.15 & 94.5 \\
\hline 7 & SO Zero, SO Nonzero & & & & & & \\
\hline & Switched Payoff Pairing & 2.84 & 5.91 & 5.91 & 2.67 & 2.67 & 92.2 \\
\hline 8 & OPT & 3.00 & 3.00 & 3.00 & 3.00 & 3.00 & 95.3 \\
\hline Average & & 2.64 & 2.60 & 2.51 & 2.29 & 2.00 & 94.0 \\
\hline Optimal & & 3 & 3 & 3 & 3 & 3 & \\
\hline
\end{tabular}

Note- $\%$ Accounted For $=$ percent of responses accounted for by most parsimonious Figure 5 model.

lying distributions (e.g., Kubovy, 1977; Kubovy \& Healy, 1980; Maloney \& Thomas, 1991). This hypothesis predicts correctly the use of a conservative decision criterion, but it fails on two accounts. First, Healy and Kubovy (1981) and Maddox and Bohil (1998a) provide evidence that responding is more nearly optimal when base rates, as opposed to costs and benefits, are manipulated. To account for this finding, the systematic misconception hypothesis would have to predict different misconceptions when base rates versus costs and benefits are manipulated. It is unclear why decisional variables, such as base rates and costs and benefits, would differentially affect knowledge of the distributions (however, see Kruschke, 1996). Second, Maddox and Bohil (1998a; see also Bohil \& Maddox, in press; Busemeyer \& Myung, 1992) provided preliminary evidence that the category level $d^{\prime}$ also affects the magnitude of conservative cutoff placement. Specifically, $d^{\prime}$ values near 1 yield conservative cutoff placement of a large magnitude, whereas $d^{\prime}$ values near 2 yield conservative cutoff placement of a smaller magnitude. Again, it is unclear how the category level $d^{\prime}$ would affect the perceived shape of the category distributions, when $d^{\prime}$ can be manipulated without affecting the shape of the distributions.

Generalized probability-matching hypothesis. Another hypothesis that has received some discussion is the generalized probability-matching hypothesis (Healy \& Kubovy, 1981; E. A. C. Thomas \& Legge, 1970). In short, it assumes that the observers select a decision criterion that matches their response probabilities to the base rates plus a constant where the constant is determined from the cost-benefit structure. We performed $t$ tests to de-

Table 2B

Most Parsimonious Figure 5 Model, $\beta$ Estimates, and Percent of Responses Accounted for by Most Parsimonious Figure 5 Model for the Experimental Conditions From the Transfer Block

\begin{tabular}{|c|c|c|c|c|c|c|c|}
\hline \multirow[b]{2}{*}{ Observer } & \multirow[b]{2}{*}{ Most Parsimonious Model } & \multicolumn{5}{|c|}{$\begin{array}{c}\beta \text { Values } \\
\text { Experimental Condition }\end{array}$} & \multirow[b]{2}{*}{$\%$ Accounted For } \\
\hline & & $2 \mathrm{a}$ & $2 \mathrm{~b}$ & $2 \mathrm{c}$ & $2 \mathrm{~d}$ & $2 \mathrm{e}$ & \\
\hline \multirow[t]{2}{*}{1} & SO Zero, SO Nonzero & & & & & & \\
\hline & High-Payoff Pairing & 1.64 & 1.01 & 2.04 & 2.04 & 1.01 & 97.5 \\
\hline 2 & SO Zero, SO Nonzero & 1.31 & 1.87 & 1.87 & 1.87 & 1.87 & 96.7 \\
\hline 3 & SO Zero, PON Nonzero & 1.97 & 1.00 & 1.00 & 1.00 & 1.00 & 94.5 \\
\hline 4 & SO Payoff & 1.30 & 1.30 & 1.30 & 1.30 & 1.30 & 89.3 \\
\hline 5 & SO Payoff & 1.31 & 1.31 & 1.31 & 1.31 & 1.31 & 96.0 \\
\hline 6 & SO Zero, SO Nonzero & 6.62 & 3.45 & 3.45 & 3.45 & 3.45 & 97.8 \\
\hline \multirow[t]{2}{*}{7} & SO Zero, SO Nonzero & & & & & & \\
\hline & Low-Payoff Pairing & 4.01 & 2.46 & 3.71 & 2.46 & 3.71 & 94.8 \\
\hline 8 & SO Payoff & 2.54 & 2.54 & 2.54 & 2.54 & 2.54 & 97.0 \\
\hline Average & & 2.59 & 1.87 & 2.15 & 2.00 & 2.02 & 95.5 \\
\hline Optimal & & 3 & 3 & 3 & 3 & 3 & \\
\hline
\end{tabular}

Note- $\%$ Accounted For $=$ percent of responses accounted for by most parsimonious Figure 5 model. 
termine whether the observed $P$ ("A") in each of the five experimental conditions was significantly larger than .50 . For the final training block, these values, averaged across observers, were $.594, .585, .572, .561$, and .583 in the Figure 2a-2e conditions, respectively. For the transfer block these values, in the same order and again averaged across observers, were $.586, .560, .570, .555$, and .565 . All $10 t$ tests were significant at the .05 level, providing evidence for the generalized probability-matching hypothesis. To determine whether the constant from the generalized probability-matching hypothesis was affected by the presence of nonzero costs, we performed one-way analyses of variance (ANOVAs) on the observed $P($ "A") for the five experimental conditions separately for the final training and transfer blocks. The ANOVAs were nonsignificant [final training block, $F(4,28)=0.966$, $p>.40$; transfer block, $F(4,28)=1.427, p>.20]$, suggesting that the constant predicted by the generalized probability-matching hypothesis is unaffected by the presence of nonzero costs.

It is worth mentioning that the generalized probabilitymatching hypothesis is noncommittal about the mechanism used to construct the decision criterion; it assumes only that the decision criterion is selected so that the $P($ "A") is equal to the base rate plus a constant. Thus, the hypothesis is not constrained to predict that the observer uses a strategy similar in spirit to that of the optimal classifier (i.e., compute the ratio of the difference between the costs and benefits). In fact, because probability matching is often nonoptimal, it is likely that the generalized probability-matching hypothesis would involve a very different set of processes underlying construction of the decision criterion. Decision bound theory assumes that observers use the same strategy as the optimal classifier (albeit in the presence of various potential suboptimalities, such as perceptual and criterial noise) and so is fundamentally at odds with the generalized probability-matching hypothesis. Because the generalized probability-matching hypothesis assumes that the observed $P($ " $\mathrm{A}$ ") is affected only by the base rates and the cost-benefit structure, other factors, such as category level $d^{\prime}$, should have no effect. The optimal classifier, on the other hand, is strongly affected by the category level $d^{\prime}$. For example, when $d^{\prime}=$ 2.155 (as in the present study), the optimal classifier will respond "A" with probability .62. However, when $d^{\prime}=1$, the optimal classifier will respond " $A$ " with a larger probability equal to .83 . Healy and Kubovy (1981) conducted a study that was similar in spirit to ours and included a condition similar to our zero-cost condition, except that the category level $d^{\prime}=1$. In their zero-cost condition, they observed a $P\left(\right.$ "A") $=.665$. Our study used a $d^{\prime}=2.155$, and, in the zero-cost condition, we observed $P($ "A") $=$ .586. Unfortunately, Healy and Kubovy (1981) did not report the probabilities for individual observers, so we are unable to determine whether this difference is statistically significant. ${ }^{4}$ Although tentative at this point, we feel that the generalized probability-matching hypothesis is insufficient because it predicts no effect of category $d^{\prime}$. Kubovy and Healy (1980) briefly reported the results of a pilot study in which $d^{\prime}$ was manipulated, and they found that $d^{\prime}$ affected the $\beta$ estimates [and thus the $P($ "A")] in a way predicted by the optimal classifier. Future research should address the relationship between category level $d^{\prime}$ and the optimality of performance.

Competition between reward and accuracy (COBRA). Maddox and Bohil (1998a) recently proposed an alternative to the generalized probabilitymatching hypothesis that accounts for the prevalence of conservative cutoff placement and the effects of $d^{\prime}$ on $P($ "A") when costs and benefits (and/or base rates) are manipulated. Unlike the generalized probability-matching hypothesis, Maddox and Bohil's (1998a) proposal assumes that the observer uses the same strategy as the optimal classifier but that there is a "competition between reward and accuracy" (COBRA) maximization. The idea is that observers attempt to maximize reward, as instructed, but also place some importance on the accuracy of their responding. When costs and benefits are manipulated, as in the present study, both goals cannot be achieved simultaneously because the decision rule that maximizes accuracy is different from the decision rule that maximizes reward (see Figure 1A). An observer who places importance on both goals will use an intermediate decision criterion and will show conservative cutoff placement. With experience, the observer might learn to adjust the weighting function in favor of reward maximization, which would lead to a shift in the observed decision criterion toward that of the optimal value. Even so, as long as some importance is assigned to accuracy maximization, conservative cutoff placement will be observed. In addition, because COBRA is driven by the goals of reward and accuracy maximization, the observed probability of responding "A" will generally be affected by the probability of responding " $A$ " predicted by each goal and thus should be affected by such factors as $d^{\prime}$. The notion that there is a competition, or tradeoff, between the accuracy of categorization responses and long-run reward likely affects nearly all categorization problems. For example, a medical doctor faces two (potentially competing) goals. One is to accurately diagnose each patient. The second is to achieve the first without adversely affecting the profit margin. The profit margin is driven by the goal to maximize long-run reward, whereas accurate diagnosis is driven by the goal to maximize long-run accuracy. When the pattern of symptoms is such that the correct diagnosis is obvious, few costly tests are needed, and high levels of accuracy and reward can be achieved simultaneously. On the other hand, when costly tests are necessary to secure an accurate diagnosis, it is possible that long-run reward may need to be sacrificed. The rise in health care costs and the proliferation of health maintenance organizations (HMOs) have increased the likelihood of this sort of accuracy-reward competition in medical decision making.

\section{Effects of Nonzero Costs}

A major finding of the present study was that the observers were closer to optimal in the zero-cost condition than in the nonzero-cost conditions, even though the per- 
formance predicted by the optimal classifier was identical across all conditions. One possibility is that the objective reward function was steeper in the zero-cost condition than in the nonzero-cost conditions. Although the category level $d^{\prime}$ was chosen to maximize the steepness of the objective reward function, this holds only relative to a fixed cost-benefit structure. Because the cost-benefit structures differ across conditions, the objective reward functions differ, although they all peak at the same $\beta$ value with the same maximum objective reward. Interestingly, the objective reward function for the zero-cost condition is the shallowest, not the steepest. Thus, if performance is driven solely by the steepness of the objective reward function, then performance should be worst, not best, in the zero-cost condition. Bohil and Maddox (in press; see also Maddox \& Bohil, 1998a) provide evidence in support of the claim that steeper objective reward functions lead to superior performance, but the present study suggests the nature of the costs has a separate, perhaps independent, effect.

An explanation that we feel has merit is that the presence of nonzero costs leads the observer toward a greater emphasis on accuracy. Within the framework of COBRA, the weight assigned to accuracy maximization would be larger when nonzero costs are present. This is a sort of differential weighting hypothesis, but, instead of postulating differential weight to the costs over the benefits, we postulate differential weight to accuracy maximization when costs are nonzero. There are at least two aspects of our data that support this claim. First, performance was worse (in terms of reward maximization) in the nonzero-cost conditions. Specifically, $\beta$ values and point totals were lower, and accuracy was higher. Second, performance declined in the nonzero-cost conditions when feedback was removed, but performance continued to improve in the zero-cost condition. Clearly, this hypothesis is tentative and awaits more rigorous testing. Even so, it does provide a reasonable account of the qualitative aspects of the data.

\section{Implications for Decision Theory}

A major goal of this research was to bridge the gap between decision making and categorization. We have made some inroads toward this goal, but we primarily focused our discussion on categorization. Even so, our hope is that decision theorists will take advantage of the database offered by this study (and detailed in Appendices A and B) and will begin to apply their models to categorization data. Promising approaches are offered by Busemeyer and Myung's (1992) hill-climbing model, Erev's (1998; see also Erev, Wallsten, \& Budescu, 1994) cutoff reinforcement learning model, and Wallsten and GonzálezVallejo's (1994) stochastic judgment model. One possibility would be to use the hill-climbing model or the cutoff reinforcement learning model as a learning mechanism for COBRA.

In conclusion, the present study extends our understanding of the use of cost-benefit knowledge in per- ceptual categorization to several situations in which the costs of incorrect responses were zero or nonzero. The cost-benefit structures were constrained in such a way that the performance of the optimal classifier was identical in each condition. In general, performance became more nearly optimal as the observers gained experience with the cost-benefit structures, but performance was consistently worse when nonzero costs were present. One possibility is that the observers placed some importance on accuracy maximization as well as reward maximization and that the presence of nonzero costs increased the emphasis on accuracy maximization.

\section{REFERENCES}

Ashry, F. G. (1992). Multidimensional models of categorization. In F. G. Ashby (Ed.), Multidimensional models of perception and cog. nition (pp. 449-484). Hillsdale, NJ: Erlbaum.

AshBY, F. G., \& GotT, R. E. (1988). Decision rules in the perception and categorization of multidimensional stimuli. Journal of Experimental Psychology: Learning, Memory, \& Cognition, 14, 33-53.

Ashby, F. G., \& LEE, W. W. (1991). Predicting similarity and categorization from identification. Journal of Experimental Psychology: General, 120, 150-172.

Ashby, F. G., \& LeE, W. W. (1993). Perceptual variability as a fundamental axiom of perceptual science. In S. C. Masin (Ed.), Foundations of perceptual theory (pp. 369-397). New York: Elsevier, NorthHolland.

AshBY, F. G., \& MADDOX, W. T. (1993). Relations between prototype, exemplar, and decision bound models of categorization. Journal of Mathematical Psychology, 37, 372-400.

AshBy, F. G., \& MADDox, W. T. (1994). A response time theory of perceptual separability and perceptual integrality in speeded classification. Journal of Mathematical Psychology, 33, 423-466.

Ashry, F. G., \& Townsend, J. T. (1986). Varieties of perceptual independence. Psychological Review, 93, 154-179.

BohIL, C. J., \& MADDOX, W. T. (in press). Category discriminability, base-rate, and payoff effects in perceptual categorization. Perception \& Psychophysics.

BusEmeyer, J. P., \& MyUng, I. J. (1992). An adaptive approach to human decision making: Learning theory, decision theory, and human performance. Journal of Experimental Psychology: General, 121, 177-194

EREV, I. (1998). Signal detection by human observers: A cutoff reinforcement learning model of categorization decisions under uncertainty. Psychological Review, 105, 280-298.

EREv, I., Wallsten, T. S., \& Budescu, D. V. (1994). Simultaneous over- and underconfidence: The role of error in judgment processes. Psychological Review, 101, 519-527.

Estes, W. K., Campbell, J. A., Hatsopoulos, N., \& Hurwitz, J. B. (1989). Base-rate effects in category learning: A comparison of parallel network and memory storage-retrieval models. Journal of Experimental Psychology: Learning, Memory, \& Cognition, 15, 556-571.

Green, D. M., \& Swets, J. A. (1966). Signal detection theory and psychophysics. New York: Wiley.

Healy, A. F., \& Kubovy, M. (1981). Probability matching and the formation of conservative decision rules in a numerical analog of signal detection. Journal of Experimental Psychology: Human Learning \& Memory, 7, 344-354.

HigGins, E. T. (1987). Self-discrepancy: A theory relating self and affect. Psychological Review, 94, 319-340.

Holyoak, K. J., \& Spellman, B. A. (1993). Thinking. Annual Review of Psychology, 44, 265-315.

Kahneman, D., \& Tversky, A. (1973). On the psychology of prediction. Psychological Review, 80, 237-251.

Kahneman, D., \& Tversky, A. (1979). Prospect theory: An analysis of decision under risk. Econometrica, 47, 263-291.

KOEHLER, J. J. (1996). The base rate fallacy reconsidered: Descriptive, 
normative, and methodological challenges. Behavioral \& Brain Sciences, 19, 1-53.

KRUSCHKE, J. K. (1996). Base-rates in category learning. Journal of Experimental Psychology: Learning, Memory, \& Cognition, 22, 3-26.

KuBovy, M. (1977). A possible basis for conservatism in signal detection and probabilistic categorization tasks. Perception \& Psychophysics, 22, 277-281.

Kubovy, M., \& Healy, A. F. (1980). Process models of probabilistic categorization. In T. S. Wallsten (Ed.), Cognitive processes in choice and decision behavior (pp. 239-262). Hillsdale, NJ: Erlbaum.

Macmillan, N. A., \& Creelman, C. D. (1991). Detection theory: A user's guide. New York: Cambridge University Press.

MADDOX, W. T. (1995). Base-rate effects in multidimensional perceptual categorization. Journal of Experimental Psychology: Learning Memory, \& Cognition, 21, 288-301.

MADDOX, W. T. (1999). On the dangers of averaging across observers when comparing decision bound and generalized context models of categorization. Perception \& Psychophysics, 61, 354-374.

Maddox, W. T., \& AshBY, F. G. (1993). Comparing decision bound and exemplar models of categorization. Perception \& Psychophysics, 53, 49-70.

Maddox, W. T., \& Ashby, F. G. (1996). Perceptual separability, decisional separability, and the identification-speeded classification relationship. Journal of Experimental Psychology: Human Perception \& Performance, 22, 795-817.

MaddoX, W. T., \& AsHBY, F. G. (1998). Selective attention and the formation of linear decision boundaries: Comment on McKinley and Nosofsky (1996). Journal of Experimental Psychology: Human Perception \& Performance, 24, 301-321.

MADDOX, W. T., \& BogDANOV, S. V. (in press). On the relation between decision rules and perceptual representation in multidimensional perceptual categorization. Perception \& Psychophysics.

MADDOX, W. T., \& BoHIL, C. J. (1998a). Base-rate and payoff effects in multidimensional perceptual categorization. Journal of Experimental Psvchology: Learning, Memory, \& Cognition, 24, 1459-1482.

MADDOX, W. T., \& BoHIL, C. J. (1998b). Overestimation of base-rate differences in complex perceptual categories. Perception \& Psychophysics, 60, 575-592.

Maloney, L. T., \& Thomas, E. A. C. (1991). Distributional assumptions and observed conservatism in the theory of signal detectability. Journal of Mathematical Psychology, 35, 443-470.

NosofSKY, R. M. (1986). Attention, similarity, and the identificationcategorization relationship. Journal of Experimental Psychology. General, 115, 39-57.
Stevenson, M. K., Busemeyer, J. R., \& NAYlor, J. C. (1991). Judgment and decision-making theory. In M. D. Dunnette \& L. M. Hough (Eds.), Handbook of industrial and organizational psychology: Vol. I (2nd ed., pp. 283-374). Palo Alto, CA: Consulting Psychologists Press.

Thomas, E. A. C., \& Legge, D. (1970). Probability matching as a basis for detection and recognition decisions. Psychological Review, 77, 65-72.

THOMAs, R. D. (1995). Gaussian general recognition theory and perceptual independence. Psychological Review, 102, 192-200.

TVERSKY, A., \& KahNEMAN, D. (1974). Judgment under uncertainty: Heuristics and biases. Science, 185, 1124-1131.

Tversky, A., \& KahNeman, D. (1980). Causal schemas in judgments under uncertainty. In M. Fishbein (Ed.), Progress in social psychology (pp. 49-72). Hillsdale, NJ: Erlbaum.

von WinTERFELDT, D., \& EDWARDS, W. (1982). Costs and payoffs in perceptual research. Psychological Bulletin, 91, 609-622.

WALlSTEN, T. S., \& GonzÁlez-VALlejo, C. C. (1994). Statement verif ication: A stochastic model of judgment and response. Psychological Review, 101, 490-504.

WICKENS, T. D. (1982). Models for behavior: Stochastic processes in psychology. San Francisco: Freeman.

YATES, J. F. (1990). Judgment and decision making. Englewood Cliffs, NJ: Prentice-Hall.

\section{NOTES}

1. Of course, there may be random variation in the physical input to the perceptual system from a fixed stimulus. For example, there might be error in the measuring device.

2 . Throughout this article, it is assumed that perceptual variance $\sigma_{p i}=$ $\sigma_{p}$. In many cases, these assumptions are incorrect (e.g., Ashby $\&$ Lee, 1991, 1993; Maddox \& Ashby, 1996, 1998; Maddox \& Bogdanov, in press), but, with high-contrast response-terminated displays and fairly simple stimuli, as in the present study, this is often a reasonable assumption. With stimulus dimensions that yield complex perceptual representations, such as hue, saturation, and brightness, or with brief stimulus displays, these assumptions would be unsatisfactory.

3. As stated earlier, the noise parameter represents the sum of perceptual and criterial noise and thus does not provide an independent estimate of criterial noise. However, since the stimuli were of high contras and the display was response terminated, it is likely that the majority of this estimate is due to the effects of criterial noise.

4. The reported value of .665 is only an estimate. Healy and Kubovy (1981) presented these data in the form of a figure, and so exact values were unavailable. 
APPENDIX A

Hit Rate for Each Experimental Condition by Observer and Block

\begin{tabular}{|c|c|c|c|c|c|c|c|c|c|c|c|c|c|}
\hline \multirow{3}{*}{ Observer } & \multirow{3}{*}{$\begin{array}{c}\text { Condition } \\
\text { (Figure) }\end{array}$} & \multirow{2}{*}{\multicolumn{5}{|c|}{ Block }} & \multirow{3}{*}{ Observer } & \multirow{3}{*}{$\begin{array}{l}\text { Condition } \\
\text { (Figure) }\end{array}$} & \multirow{2}{*}{\multicolumn{5}{|c|}{ Block }} \\
\hline & & & & & & & & & & & & & \\
\hline & & 1 & 2 & 3 & 4 & 5 & & & 1 & 2 & 3 & 4 & 5 \\
\hline \multirow[t]{5}{*}{1} & $2 a$ & .917 & .900 & .917 & .900 & .900 & 1 & $2 a$ & .200 & .217 & .150 & .217 & .183 \\
\hline & $2 b$ & .867 & .900 & .883 & .900 & .883 & & $2 b$ & .150 & .167 & .200 & .200 & .167 \\
\hline & $2 c$ & .917 & .867 & .917 & .883 & .950 & & $2 c$ & .217 & .183 & .200 & .183 & .200 \\
\hline & $2 d$ & .917 & .883 & .917 & .933 & .900 & & $2 d$ & .233 & .233 & .167 & .167 & .217 \\
\hline & $2 e$ & .850 & .850 & .850 & .833 & .850 & & $2 e$ & .117 & .117 & .150 & .100 & .133 \\
\hline \multirow[t]{5}{*}{2} & $2 a$ & .900 & .917 & .883 & .917 & .900 & 2 & $2 a$ & .133 & .150 & .217 & .233 & .167 \\
\hline & $2 b$ & .883 & .883 & .900 & .900 & .917 & & $2 b$ & .167 & .200 & .167 & .133 & .167 \\
\hline & $2 c$ & .900 & .933 & .883 & .917 & .917 & & $2 \mathrm{c}$ & .200 & .233 & .217 & .233 & .233 \\
\hline & $2 \mathrm{~d}$ & .883 & .933 & .933 & .933 & .917 & & $2 d$ & .200 & .183 & .200 & .267 & .233 \\
\hline & $2 e$ & .900 & .867 & .900 & .883 & .900 & & $2 \mathrm{e}$ & .200 & .167 & .167 & .183 & .200 \\
\hline \multirow[t]{5}{*}{3} & $2 a$ & .900 & .883 & .867 & .883 & .900 & 3 & $2 a$ & .217 & .250 & .200 & .217 & .233 \\
\hline & $2 b$ & .917 & .917 & .917 & .900 & .867 & & $2 b$ & .183 & .217 & .233 & .267 & .183 \\
\hline & $2 c$ & .850 & .833 & .750 & .783 & .867 & & $2 c$ & .150 & .150 & .117 & .167 & .133 \\
\hline & $2 d$ & .800 & .850 & .817 & .867 & .867 & & $2 d$ & .150 & .200 & .167 & .217 & .133 \\
\hline & $2 e$ & .850 & .867 & .867 & .883 & .833 & & $2 \mathrm{e}$ & .167 & .217 & .150 & .233 & .167 \\
\hline \multirow[t]{5}{*}{4} & $2 a$ & .833 & .900 & .900 & .900 & .900 & 4 & $2 a$ & .183 & .233 & .233 & .283 & .217 \\
\hline & $2 b$ & .850 & .883 & .817 & .833 & .817 & & $2 b$ & .333 & .233 & .133 & .217 & .267 \\
\hline & $2 c$ & .783 & .917 & .883 & .850 & .800 & & $2 c$ & .150 & .200 & .150 & .183 & .183 \\
\hline & $2 d$ & .867 & .917 & .950 & .900 & .917 & & $2 \mathrm{~d}$ & .167 & .233 & .217 & .300 & .200 \\
\hline & $2 \mathrm{e}$ & .833 & .850 & .783 & .833 & .817 & & $2 \mathrm{e}$ & .250 & .183 & .183 & .133 & .167 \\
\hline \multirow[t]{5}{*}{5} & $2 a$ & .950 & .933 & .950 & .950 & .933 & 5 & $2 a$ & .267 & .267 & .283 & .283 & .383 \\
\hline & $2 b$ & .867 & .917 & .967 & .933 & .933 & & $2 b$ & .183 & .400 & .633 & .467 & .317 \\
\hline & $2 c$ & .950 & .967 & .983 & .950 & .933 & & $2 c$ & .350 & .450 & .383 & .433 & .367 \\
\hline & $2 d$ & .983 & .933 & .950 & .917 & .933 & & $2 d$ & .350 & .267 & .300 & .233 & .200 \\
\hline & $2 \mathrm{e}$ & .883 & .933 & .967 & .950 & .933 & & $2 \mathrm{e}$ & .150 & .333 & .333 & .317 & .333 \\
\hline \multirow[t]{5}{*}{6} & $2 a$ & .900 & .867 & .917 & .850 & .867 & 6 & $2 a$ & .267 & .183 & .283 & .250 & .167 \\
\hline & $2 b$ & .883 & .883 & .833 & .883 & .867 & & $2 b$ & .167 & .183 & .217 & .200 & .167 \\
\hline & $2 c$ & .917 & .867 & .900 & .900 & .883 & & $2 \mathrm{c}$ & .317 & .167 & .333 & .183 & .217 \\
\hline & $2 \mathrm{~d}$ & .850 & .883 & .900 & .867 & .900 & & $2 d$ & .167 & .267 & .150 & .183 & .150 \\
\hline & $2 \mathrm{e}$ & .850 & .917 & .917 & .883 & .883 & & $2 \mathrm{e}$ & .150 & .233 & .167 & .183 & .133 \\
\hline \multirow[t]{5}{*}{7} & $2 a$ & .933 & .933 & .933 & .917 & .950 & 7 & $2 a$ & .233 & .250 & .233 & .317 & .250 \\
\hline & $2 b$ & .933 & .933 & .967 & .933 & .917 & & $2 b$ & .250 & .367 & .333 & .350 & .283 \\
\hline & $2 c$ & .950 & .933 & .950 & .933 & .933 & & $2 c$ & .250 & .233 & .250 & .233 & .233 \\
\hline & $2 d$ & .933 & .950 & .933 & .950 & .950 & & $2 d$ & .283 & .317 & .217 & .267 & .250 \\
\hline & $2 \mathrm{e}$ & .917 & .933 & .933 & .933 & .967 & & $2 \mathrm{e}$ & .217 & .250 & .283 & .300 & .267 \\
\hline \multirow[t]{5}{*}{8} & $2 a$ & .967 & .967 & .983 & .983 & .983 & 8 & $2 \mathrm{a}$ & .417 & .433 & .433 & .400 & .450 \\
\hline & $2 \mathbf{b}$ & .967 & .950 & .967 & .950 & .967 & & $2 b$ & .350 & .267 & .233 & .300 & .250 \\
\hline & $2 c$ & .950 & .967 & .950 & .967 & .950 & & $2 c$ & .383 & .383 & .333 & .350 & .317 \\
\hline & $2 d$ & .950 & .967 & .950 & .967 & .950 & & $2 d$ & .250 & .350 & .417 & .367 & .317 \\
\hline & $2 \mathrm{e}$ & .967 & .983 & .950 & .983 & .967 & & $2 \mathrm{e}$ & .300 & .300 & .333 & .350 & .333 \\
\hline \multirow[t]{5}{*}{ Average } & $2 \mathbf{a}$ & .913 & .913 & .919 & .913 & .917 & Average & $2 \mathrm{a}$ & .240 & .248 & .254 & .275 & .256 \\
\hline & $2 b$ & .896 & .908 & .906 & .904 & .896 & & $2 b$ & .223 & .254 & .269 & .267 & .225 \\
\hline & $2 c$ & .902 & .910 & .902 & .898 & .904 & & $2 c$ & .252 & .250 & .248 & .246 & .235 \\
\hline & $2 d$ & .898 & .915 & .919 & .917 & .917 & & $2 d$ & .225 & .256 & .229 & .250 & .213 \\
\hline & $2 \mathrm{e}$ & .881 & .900 & .896 & .898 & .894 & & $2 \mathrm{e}$ & .194 & .225 & .221 & .225 & .217 \\
\hline
\end{tabular}

\section{APPENDIX B}

False-Alarm Rate for Each Experimental Condition by Observer and Block 